\title{
Hypolipidaemic effects of fenofibrate and fasting in the herbivorous grass carp (Ctenopharyngodon idella) fed a high-fat diet
}

\author{
Zhen-Yu Du ${ }^{1,2,3 *}$, Pierre Clouet $^{2}$, Pascal Degrace ${ }^{2}$, Wen-Hui Zheng ${ }^{4}$, Livar Frøyland $^{3}$, Li-Xia Tian ${ }^{1}$ \\ and Yong-Jian $\mathrm{Liu}^{1}{ }^{1}$ \\ ${ }^{1}$ Institute of Aquatic Economic Animals, School of Life Sciences, Sun Yat-sen University, 135 Xin'gang Xi Road, \\ 510275 Guangzhou, China \\ ${ }^{2}$ UMR 866 INSERM-UB, Equipe Physiopathologie des Dyslipidémies, Faculté des Sciences, Université de Bourgogne, \\ 21000 Dijon, France \\ ${ }^{3}$ National Institute of Nutrition and Seafood Research (NIFES), PO Box 2029, Nordnes, N-5817 Bergen, Norway \\ ${ }^{4}$ Zhongshan School of Medicine, Sun Yat-sen University, 510089 Guangzhou, China \\ (Received 7 August 2007 - Revised 28 February 2008 - Accepted 1 March 2008 - First published online 29 April 2008)
}

\begin{abstract}
We investigated whether the hypolipidaemic effect of fenofibrate and fasting observed in most omnivorous mammals may also apply to herbivorous fish. Grass carp (Ctenopharyngodon idella) fed a high-fat $(8 \%)$ diet exhibited a marked increase in blood lipids and body fat after 6 weeks. They were then treated with fenofibrate $(100 \mathrm{mg} / \mathrm{kg}$ body weight) in the same high-fat diet for 2 weeks, followed by fasting for 1 week. Plasma lipid concentration, body fat amount, fatty acid composition, plasma thiobarbituric acid-reactive substances and some parameters related to hepatic fatty acid oxidation were measured, and liver samples were stained for histological examination. Fenofibrate treatment decreased TAG and cholesterol concentrations in plasma, total lipids of the whole body and liver, and EPA and DHA contents in tissues. Further, a mobilisation of mesenteric fat concomitant with an increase in hepatic peroxisomal fatty acid oxidation and lipid peroxidation was observed. Compared with fenofibrate treatment, fasting decreased body weight and plasma TAG, but not plasma cholesterol. It also reduced the fat content of the whole body and increased the EPA and DHA contents in the liver and other tissues. Fatty acid oxidation was stimulated by fasting in mitochondria, but not in peroxisomes. These data suggest that fenofibrate and fasting regulate the lipid metabolism in grass carp through different metabolic pathways. The grass carp is moderately responsive to a fibrate derivative in comparison with the well-known excess responsiveness of the rat model, and so it could be used for the study of lipid abnormalities as a herbivorous model.
\end{abstract}

Grass carp: Fenofibrate: Fasting: High-fat diets: Hyperlipidaemia: $\beta$-Oxidation

Fibrate derivatives are widely used as normolipidaemic or hypolipidaemic drugs for the treatment of hypertriacylglycerolaemic and/or hypercholesterolaemic patients ${ }^{(1-3)}$. As a lipid-lowering agent, fenofibrate has been shown to lower the concentration of plasma TAG and cholesterol ${ }^{(4,5)}$. Some mechanisms of clinical effects of fenofibrate have been identified, including interference with fatty acid (FA) synthesis, stimulation of hepatic FA oxidation, increase in lipoprotein lipolysis, inhibition of cholesterol biosynthesis, induction of hepatic uptake of cholesterol from plasma and increased elimination of cholesterol into bile as biliary acids ${ }^{(6)}$. Fenofibrate is also known to activate the transcriptional factor $\operatorname{PPAR} \alpha$, which binds to the peroxisome proliferator response element in the regulatory region of target genes ${ }^{(7,8)}$. By this way, PPAR $\alpha$ is known to induce enzymes involved in the regulation of lipid metabolism, particularly those related to mitochondrial and peroxisomal FA oxidation ${ }^{(9-12)}$. It has also been suggested that fenofibrate regulates body weight (BW) and energy homeostasis by increasing FA oxidation ${ }^{(13)}$.

Similarly to fibrate derivatives, fasting also activates $\operatorname{PPAR} \alpha$ and thereby regulates mitochondrial and peroxisomal FA oxidation activities ${ }^{(14,15)}$. The regulation of these pathways affects the lipid metabolism and was effectively demonstrated to modulate blood lipid composition in both animal models and humans ${ }^{(16-18)}$. The observations regarding blood lipid alteration during fasting are conflicting ${ }^{(17-21)}$, but hypolipidaemic effects have been reported ${ }^{(18,22)}$.

The hypolipidaemic effects of fenofibrate and fasting have been shown in mammals, but little information is available in fish. Previous studies indicated that, in rainbow trout fed a $22 \%$ fat diet, the level of peroxisomal FA oxidation was increased by fenofibrate with a concomitant decrease in body EPA and $\mathrm{DHA}^{(23)}$. Contrasting with the carnivorous rainbow trout, grass carp (Ctenopharyngodon idella) is a typical herbivorous finfish. Recent studies showed that the energy

Abbreviations: BW, body weight; CPT I, carnitine palmitoyltransferase I; FA, fatty acid; HDL-C, HDL-cholesterol; HF, high-fat; LDL-C, LDL-cholesterol; TBARS, thiobarbituric acid-reactive substances.

* Corresponding authors: Dr Zhen-Yu Du, fax +47 5590 5298, email zdu@nifes.no; Professor Yong-Jian Liu, fax + 862084115896 , email edls@mail.sysu.edu.cn 
requirement of grass carp was relatively lower than that of most carnivorous fish species. High-fat (HF) diets (above $6 \%$ fat), especially with high levels of PUFA, resulted in lowered feed intake, decreased growth, accumulation of lipids in the liver and other organs, alteration of lipoprotein synthesis, high plasma TAG and cholesterol, and elevated LDL-cholesterol (LDL-C) ${ }^{(24-26)}$. Under these conditions, it would be interesting to know whether grass carp possesses sufficient potential capacities to utilise excess dietary lipids. The aim of the present study was therefore to increase the lipid catabolism in grass carp fed an HF diet by using fenofibrate as a potent ligand of PPAR $\alpha$ and fasting that represents a usual physiological condition. Further, since fenofibrate is used to treat hyperlipidaemic patients, it could also be capable of curing fish with hyperlipidaemia symptoms. Since fasting is shown to regulate several genes involved in lipid metabolism in a similar manner as fenofibrate in mammals ${ }^{(15)}$, comparable effects could be expected in our herbivorous fish model.

In the present study, to evaluate the possible hypolipidaemic effect of fenofibrate and fasting in grass carp, juvenile grass carp were fed an HF diet for 6 weeks and then treated with fenofibrate for 2 weeks, followed by 1 week of fasting to the end of the study. Nutritional and biochemical measurements including body composition, blood lipids, peroxidation products and hepatic FA mitochondrial and peroxisomal $\beta$-oxidation were performed to evaluate the extent of biochemical alterations induced by fenofibrate and fasting.

\section{Materials and methods}

\section{Fish and diets}

Juvenile grass carp, initially weighing (7.83 (SE 0.11) g, were distributed into six glass tanks with recirculation (300 litres; thirty fish per tank) maintained at $28^{\circ} \mathrm{C}$ with a $12 \mathrm{~h}$ lightdark cycle. Fish were acclimatised to experimental conditions for 2 weeks during which fish were fed the lipid-free experimental diet (gross energy; $9673 \mathrm{~kJ} / \mathrm{kg}$ ) at $1 \% \mathrm{BW} / \mathrm{d}$. An HF diet, whose composition is detailed in Table 1, was prepared as previously described ${ }^{(24)}$ and freeze dried for further use as the HF diet. Fenofibrate, provided by Professor P. Clouet (UMR 866, Dijon, France), was added to the HF diet ( $0 \cdot 34 \%$ $\mathrm{DM})$ as indicated in Table 1 . HF and $\mathrm{HF}+$ fenofibrate diets were transformed into $1.5 \mathrm{~mm}$ pellets (about $10.5 \%$ moisture). All fish were fed the HF diet for 6 weeks (weeks 1-6) at a feeding rate of $3 \% \mathrm{BW} / \mathrm{d}$ to induce body fat accumulation. After this period, the average fish weight in the two groups was $12 \cdot 1($ SE $0 \cdot 2) \mathrm{g}$ and did not significantly differ between tanks. Fish of one group were then fed the HF diet containing $0.34 \%$ fenofibrate for the next 2 weeks (weeks 7 and 8) at the same feeding rate, which provided $100 \mathrm{mg}$ fenofibrate $/ \mathrm{kg} \mathrm{BW}$ per $d$ (the usual dose active in rats). During the feeding trial, fish were fed at 09.00 and 18.00 hours with an equal portion of diet, and were weighed once per week. At the end of the 8 -week feeding trial, the water in the tanks was totally renewed and the fish of both groups were fasted for 1 week (week 9). The detailed trial protocol is shown in Fig. 1. During the whole experimental period, faeces were siphoned from tanks using a rubber pipe every morning, while dissolved $\mathrm{O}_{2}, \mathrm{pH}$ and ammonia were maintained at $7.74(\mathrm{SE} 0 \cdot 61) \mathrm{mg} / \mathrm{l}$, $7 \cdot 21(\mathrm{SE} 0 \cdot 20)$ and $0 \cdot 15(\mathrm{SE} 0 \cdot 05) \mathrm{mg} / \mathrm{l}$, respectively.
Table 1. Composition of experimental diets (\% dry weight)

\begin{tabular}{lcc} 
& HF diet & HF + fenofibrate diet \\
\hline Casein & 28.44 & 28.44 \\
Gelatin & $7 \cdot 11$ & 7.11 \\
Dextrin & 25 & 25 \\
Plant oil mixture* & 3 & 3 \\
Fish oil† & 5 & 5 \\
Cellulose & 19.95 & 19.61 \\
Vitamin mix & 2 & 2 \\
Mineral mix§ & 8 & 8 \\
Ascorbic phosphate ester & 1 & 1 \\
Choline chloride & 0.5 & 0.5 \\
Fenofibrate & - & 0.34 \\
Proximate composition (determined value) & \\
Crude protein & 31.5 & 31.5 \\
Crude lipid & 7.88 & 7.92 \\
Carbohydratell & 24.6 & 24.2 \\
Moisture & 9.65 & 9.55 \\
Ash & 6 & 5.8
\end{tabular}

$\mathrm{HF}$, high-fat.

* The plant oil mixture contained mainly maize oil and linseed oil.

$\dagger$ In this commercial product, butylated hydroxytoluene was added at $1 \mathrm{~g} / \mathrm{kg}$ to avoid lipid peroxidation.

$\ddagger$ The vitamin mix (Evergreen Feed Co., Guangzhou, China) contained (mg/kg diet): thiamin, 50; riboflavin, 50; vitamin $A, 9$; vitamin $E, 400$; vitamin $D_{3}, 6$; menadione, 40; pyridoxine $\mathrm{HCl}, 40$; cyanocobalamin, 0.1 ; biotin, 6 ; calcium pantothenate, 100; folic acid, 15; niacin, 200; inositol, 2000. Cellulose was used as a carrier.

$\S$ The mineral mix (Evergreen Feed Co., Guangzhou, China) contained (mg/kg diet): calcium biphosphate, 9.8; calcium lactate, 37.9; sodium chloride, 2.6; potassium sulfate, 13.1; potassium chloride, $5 \cdot 3$; ferrous sulfate, 0.9 ; ferric citrate, 3.1; magnesium sulfate, 3.5; zinc sulfate, 0.04; manganese sulfate, 0.03; cupric sulfate, 0.02; cobalt chloride, 0.03; potassium iodide, 0.002; cellulose, 42 $\|$ Cellulose excluded.

\section{Sampling procedure and chemical analysis of organs}

After the first 6 weeks of the feeding trial, four fish were randomly captured from each tank, fasted for $24 \mathrm{~h}$ and regrouped for whole-body and blood chemical analysis (four fish from six tanks, totalling twenty-four fish). After fenofibrate treatment and the following fasting for 1 week, six fish were randomly captured from each tank and regrouped for whole-body and blood chemical analysis (six fish from three tanks per treatment, totalling eighteen fish per treatment). Another six fish randomly captured from each tank were killed by spinal destruction and used for individual measurements of BW and length, and weights of viscera, liver, mesenteric fat tissue and white muscle (eighteen fish per treatment). Pieces of liver, mesenteric fat tissue and white muscle from both sides of the spine (fillets) without skin were stored at $-20^{\circ} \mathrm{C}$ until analysis. Total $\mathrm{N}$ and carbohydrate of the diets and body samples were measured by the Kjeldahl method using an auto-analyser (Tecator Kjelte model 1030; Tecator $\mathrm{AB}$, Höganäs, Sweden) and the $3^{\prime} 5$-dinitrosalicylic acid $\operatorname{method}^{(27)}$, respectively.

\section{Lipid analysis by GLC}

Total lipids of the diet, muscle, liver and mesenteric fat tissue were extracted according to the method of Bligh \& Dyer ${ }^{(28)}$. FA from lipid extracts were methylated with $10 \%$ potassium hydroxide in methanol for $1 \mathrm{~h}$ at room temperature. FA methyl esters were then analysed and quantified using a Hewlett-Packard HP-5890 gas chromatograph in a cross-linked $5 \%$ phenylmethyl silicone gum phase 


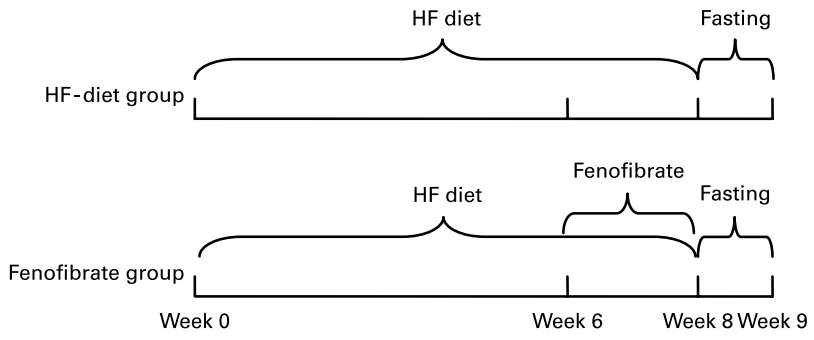

Fig. 1. Experimental protocol of feeding and fasting trial. HF, high-fat.

column (length $25 \mathrm{~m}$, internal diameter $0.32 \mathrm{~mm}$, film thickness $0.25 \mu \mathrm{m}$; HP-Ultra 2, with $\mathrm{N}_{2}$ as the carrier gas), equipped with flame ionisation detection. The injector and detector temperatures were 280 and $300^{\circ} \mathrm{C}$, respectively. The column temperature set at $190^{\circ} \mathrm{C}$ was then increased to $260^{\circ} \mathrm{C}\left(2^{\circ} \mathrm{C} / \mathrm{min}\right)$ and held for $5 \mathrm{~min}$. Each FA was identified using a mixture of standard FA methyl esters (Cayman Co., Ann Arbor, MI, USA). Results were expressed as the percentage of each FA with respect to total FA.

\section{Plasma analysis}

Blood collected from the heart with a heparinised microsyringe was immediately centrifuged. Plasma samples were frozen at $-30^{\circ} \mathrm{C}$ until analysis. Plasma TAG, total cholesterol, HDL-cholesterol (HDL-C), LDL-C and apo A-I were assayed by enzymic procedures using an automatic biochemical analyser (Hitachi 7170, Tokyo, Japan) and attached kits (Daiichi Pure Chemicals Co., Ltd, Tokyo, Japan). TAG and cholesterol were assessed by the glucose oxidase-peroxidase (GOD-PAP) method ${ }^{(29)}$ and the cholesterol oxidase-peroxidase (CHOD-PAP) method ${ }^{(30)}$, respectively. HDL-C and LDL-C were assessed by enzymic methods ${ }^{(31,32)}$, and apo A-I by immunoassay ${ }^{(33)}$. Thiobarbituric acid-reactive substances (TBARS) were quantified as described by Rueda-Jasso et al. ${ }^{(34)}$ using the malondialdehyde kit (Jiancheng Biotech Co., Nanjing, China).

\section{Histology}

Livers from three fish were sampled from each tank and prepared for histological examination. Pieces of liver were fixed in $10 \%$ formaldehyde and embedded in paraffin. Sections of $5 \mu \mathrm{m}$ thickness were stained with the Harris haematoxylin-eosin mixture and examined under a light microscope ${ }^{(35)}$.

\section{Liver homogenates and mitochondrial fraction preparations}

After treatments of fenofibrate and fasting, pieces of liver (about $3 \mathrm{~g}$ ) collected from each group were cut finely in ice-cold $0.25 \mathrm{M}$-sucrose medium containing $1 \mathrm{~mm}$-EGTA and $10 \mathrm{~mm}$-2-amino-2-hydroxymethyl-propane-1,3-diol- $\mathrm{HCl}$, $\mathrm{pH} 7 \cdot 4$, rinsed five times in the same medium, blotted with absorbent paper and weighed. The tissue was diluted (1:20, $\mathrm{w} / \mathrm{v})$ in the chilled sucrose medium and homogenised by only four strokes of a Teflon pestle rotating at $300 \mathrm{rpm}$ in a Potter-Elvehjem homogeniser (Wheaton Science Products, Millville, NJ, USA). The $1 \mathrm{ml}$ samples of homogenate were kept apart for the immediate measurement of mitochondrial and peroxisomal palmitate oxidation levels (see below) and the delayed measurement of marker enzyme activities. The remaining homogenate was 2-fold diluted with sucrose medium containing $2 \%$ FA-free bovine serum albumin and was centrifuged at $2500 \mathrm{~g}$ for $4 \mathrm{~min}$ at $4^{\circ} \mathrm{C}$. The supernatant fraction was immediately centrifuged at $16000 \mathrm{~g}$ for $6 \mathrm{~min}$ and the pellet obtained was re-suspended with the sucrose medium without bovine serum albumin and re-sedimented using the preceding conditions. The procedure was repeated once and the pellet re-suspended in $1 \mathrm{ml}$ of buffered $0.3 \mathrm{M}$ sucrose was used as the mitochondrial fraction. The protein content of this fraction was roughly estimated by a rapid spectrophotometric method ${ }^{(36)}$, which allowed the immediate measurement of the activity levels of palmitate oxidation and carnitine palmitoyltransferase I (CPT I). These measurements were corrected later after more accurate determination of the protein content with the bicinchoninic acid method ${ }^{(37)}$.

\section{Mitochondrial and peroxisomal enzyme assays}

The presence of mitochondria was assessed by the activity of monoamine oxidase ${ }^{(38)}$. The mitochondrial protein content per $g$ liver was calculated by dividing the activity of monoamine oxidase per $\mathrm{g}$ liver (measured in total homogenate) by the activity expressed per $\mathrm{mg}$ mitochondrial protein (measured in the mitochondrial fraction). The presence of peroxisomes was assessed by the activity of catalase ${ }^{(39)}$, and of $\mathrm{CN}^{-}$-insensitive palmitoyl-CoA-dependent $\mathrm{NAD}^{+}$reduction, a short sequence of enzymes acting at the beginning of the $\beta$-oxidation cycle, described as the peroxisomal FA-oxidising system $^{(40)}$. CPT I activity measurement was carried out using ${ }^{3} \mathrm{H}$-labelled L-carnitine and palmitoyl-CoA ${ }^{(41)}$, and extraction of the palmitoyl- $\left[{ }^{3} \mathrm{H}\right]$ carnitine produced was performed using butan-1-ol. The associated radioactivity was counted in the presence of a convenient $(1: 6, \mathrm{v} / \mathrm{v})$ scintillation cocktail $^{(42)}$ in a liquid scintillation spectrometer (LS3500; Beckman, Fullerton, CA, USA).

\section{Liver mitochondrial and peroxisomal palmitate oxidation}

From liver homogenates. Homogenates originated from pieces of liver homogenised in 20 vol. sucrose medium as indicated above and were used as soon as possible. Palmitate oxidation rates were measured at $37^{\circ} \mathrm{C}$ using two media as already described ${ }^{(43)}$, the first allowing the mitochondrial and peroxisomal activities to occur, the second allowing the peroxisomal activity only. After $30 \mathrm{~min}$, the radioactivity initially held by $\left[1-{ }^{14} \mathrm{C}\right]$ palmitate was recovered on labelled short molecules released from the $\beta$-oxidative cycle and soluble in perchloric acid (acid-soluble products) using 0.45 membrane filters (Millipore, Billerica, MA, USA). The radioactivity of the acid-soluble products was measured as above for that of butan-1-ol extracts.

From liver mitochondria. Isolated mitochondria were used to assess whether activity rates related to mitochondria previously measured in liver homogenates were not altered by the presence of extra-mitochondrial compounds and/or enzyme reactions. The medium contained $\left[1-{ }^{14} \mathrm{C}\right]$ palmitate bound to bovine serum albumin in a 1.5:1 molar ratio, and the incubation was stopped after $8 \mathrm{~min}$ with perchloric acid. 
The radioactivity of the acid-soluble products was measured as the method indicated above for liver homogenates.

\section{Statistical analysis}

Results are expressed as mean values with their standard errors. Significant differences $(P<0.05)$ of each variable were first detected using the one-way ANOVA test, and then the Duncan's multiple-range test was used to rank the four experimental groups. All analyses were made using the SPSS 9.0 software (SPSS Inc., Chicago, IL, USA).

\section{Results}

Body parameters, total tissue lipid and hepatic histology

In grass carp fed the HF diet for 6 weeks, there was no significant difference in mean values between tanks for all the parameters tested (Tables 2 and 3). The whole-body fat mass was nearly $60 \%$ greater than in fish fed a fat-free diet or a low-fat diet as previously shown ${ }^{(24-26,44)}$, and was associated with hyperlipidaemia symptoms. Fenofibrate administered during the last 2 weeks of the 8-week HF-diet feeding period did not affect the weight of the whole body, viscera, white muscle and liver, but significantly decreased the weight of mesenteric fat tissue compared with fish fed the HF diet for 8 weeks (Table 2). The final fasting for 1 week applied to both groups significantly decreased whole-body, liver and mesenteric fat tissue weights, but there was still a significant difference in the relative mass of mesenteric fat tissue between the fenofibrate and HF-diet groups. Table 3 shows that the fenofibrate treatment significantly reduced the lipid content of the whole body and liver, relative to the HF-diet group. The final week of fasting resulted in a decrease in lipids of the whole body, white muscle and mesenteric fat tissue, but significant differences were only found in whole-body lipid contents for each group (without or with fenofibrate), and in white muscle lipid contents only for the fenofibrate group. The significant differences in whole-body lipid contents existing between the HF-diet and fenofibrate groups still persisted after fasting. Compared with the lipid content of whole-body, muscle and mesenteric fat tissue, liver lipid content conversely increased significantly after fasting for 1 week, but the significant difference that existed between the two groups was not observed after fasting (Table 3). The histological study of liver showed that, in fish fed the HF diet (Fig. 2 (a)), hepatocytes were swollen with numerous clear round areas of various sizes (corresponding to lipid droplets whose initial content was eliminated during the staining procedure) occupying most space and pushing nuclei aside to cell periphery. In the fenofibrate group (Fig. 2 (b)), steatotic hepatocytes with varying size lipid droplets were also found, but were less numerous than in the liver of the HF-diet group. After 1 week of fasting, the number of swollen hepatocytes appeared to increase in both dietary groups (Fig. 2 (c) and (d)), and there was no apparent visible difference between hepatocytes of the HF-diet and fenofibrate groups.

\section{Plasma lipids and thiobarbituric acid-reactive substances}

As shown in Table 3, except for HDL-C, the plasma contents of TAG, cholesterol, LDL-C and apo A-I were all significantly lowered after fenofibrate treatment. After the final fasting, there was no more difference in plasma lipid indexes between fish previously treated with or not with fenofibrate, except for plasma TAG that were still more reduced in fish previously treated by fenofibrate. Fenofibrate treatment significantly increased the plasma TBARS concentration, but this increase disappeared after the fasting period.

\section{Fatty acid composition in diet and tissues}

The dietary lipid source was a mixture of maize, linseed and fish oils, and was characterised by its high contents of oleic acid $(17.7 \%)$, linoleic acid (25.6\%), EPA (4.97\%) and DHA $(24.7 \%)$. The dietary FA distribution is given for reference in Tables 4-6, which show the FA composition of white muscle, liver and mesenteric fat tissue, respectively. The FA composition was altered by fenofibrate and fasting only in white muscle and liver, but not in mesenteric fat tissue. In the former

Table 2. Effect of fenofibrate treatment and fasting on body parameters in juvenile grass carp (Ctenopharyngodon idella) fed a high-fat (HF) diet (Mean values with their standard errors)

\begin{tabular}{|c|c|c|c|c|c|c|c|c|c|c|}
\hline & \multicolumn{6}{|c|}{ Continuous feeding } & \multicolumn{4}{|c|}{ Final fasting (week 9) } \\
\hline & \multicolumn{2}{|c|}{$\begin{array}{l}\text { HF-diet group } \\
\text { (weeks 1-6) }\end{array}$} & \multicolumn{2}{|c|}{$\begin{array}{l}\text { HF-diet group } \\
\text { (weeks 1-8) }\end{array}$} & \multicolumn{2}{|c|}{$\begin{array}{l}\text { Fenofibrate group } \\
\text { (weeks 7-8) }\end{array}$} & \multicolumn{2}{|c|}{$\begin{array}{l}\text { HF-diet group } \\
\text { (weeks 1-8) }\end{array}$} & \multicolumn{2}{|c|}{$\begin{array}{l}\text { Fenofibrate group } \\
\quad \text { (weeks 7-8) }\end{array}$} \\
\hline & Mean & SEM & Mean & SEM & Mean & SEM & Mean & SEM & Mean & SEM \\
\hline Body weight (g) & $12 \cdot 1$ & 0.2 & $16 \cdot 3^{b}$ & 0.8 & $15 \cdot 8^{\mathrm{b}}$ & 0.7 & $11.9^{\mathrm{a}}$ & 0.6 & $10 \cdot 7^{\mathrm{a}}$ & 0.6 \\
\hline Condition factor ${ }^{\star}$ & $2 \cdot 27$ & 0.08 & 2.35 & 0.07 & $2 \cdot 19$ & 0.08 & 2.24 & 0.03 & $2 \cdot 16$ & 0.07 \\
\hline White muscle index $\dagger$ & $64 \cdot 3$ & $5 \cdot 8$ & $65 \cdot 7$ & $3 \cdot 7$ & $67 \cdot 2$ & 2.4 & $68 \cdot 6$ & $2 \cdot 1$ & $69 \cdot 8$ & $2 \cdot 3$ \\
\hline Viscera index $\ddagger$ & $12 \cdot 1$ & 0.8 & $12 \cdot 5$ & 0.6 & 11.9 & 0.5 & $10 \cdot 8$ & 0.6 & $10 \cdot 6$ & 0.3 \\
\hline Hepatosomatic index§ & 3.08 & 0.34 & $3.41^{\mathrm{b}}$ & 0.28 & $3 \cdot 34^{\mathrm{b}}$ & 0.20 & $2 \cdot 03^{a}$ & 0.15 & $2 \cdot 03^{a}$ & 0.16 \\
\hline Mesenteric fat index\| & $3 \cdot 11$ & 0.34 & $3 \cdot 28^{\mathrm{c}}$ & 0.20 & $2 \cdot 30^{\mathrm{b}}$ & 0.09 & $2 \cdot 34^{\mathrm{b}}$ & 0.08 & $1.88^{\mathrm{a}}$ & 0.07 \\
\hline
\end{tabular}

a,b,c Mean values (excluding those for the HF-diet group weeks $1-6$ ) within a line with unlike superscript letters were significantly different $(P<0.05)$.

${ }^{*}$ Condition factor $=$ fish weight $(\mathrm{g}) \times 100 /$ body length ${ }^{3}(\mathrm{~cm})$.

† White muscle index $=$ white muscle weight $\times 100 /$ fish weight.

$\ddagger$ Viscera index $=$ viscera weight $\times 100$ /fish weight.

$\S$ Hepatosomatic index $=$ liver weight $\times 100 /$ fish weight

$\|$ Mesenteric fat index $=$ mesenteric fat tissue weight $\times 100 /$ fish weight. 
Table 3. Effect of fenofibrate treatment and fasting on body lipid contents, plasma lipid parameters and thiobarbituric acid-reactive substances (TBARS) in juvenile grass carp (Ctenopharyngodon idella) fed a high-fat (HF) diet

(Mean values with their standard errors)

\begin{tabular}{|c|c|c|c|c|c|c|c|c|c|c|}
\hline & \multicolumn{6}{|c|}{ Continuous feeding } & \multicolumn{4}{|c|}{ Final fasting (week 9) } \\
\hline & \multicolumn{2}{|c|}{$\begin{array}{l}\text { HF-diet group } \\
\text { (weeks 1-6) }\end{array}$} & \multicolumn{2}{|c|}{$\begin{array}{l}\text { HF-diet group } \\
\text { (weeks 1-8) }\end{array}$} & \multicolumn{2}{|c|}{$\begin{array}{l}\text { Fenofibrate group } \\
\text { (weeks 7-8) }\end{array}$} & \multicolumn{2}{|c|}{$\begin{array}{l}\text { HF-diet group } \\
\text { (weeks 1-8) }\end{array}$} & \multicolumn{2}{|c|}{$\begin{array}{l}\text { Fenofibrate group } \\
\quad \text { (weeks } 7-8 \text { ) }\end{array}$} \\
\hline & Mean & SEM & Mean & SEM & Mean & SEM & Mean & SEM & Mean & SEM \\
\hline \multicolumn{11}{|l|}{ Lipid content (weight \%) } \\
\hline Whole body & 8.21 & 0.08 & $8.87^{d}$ & 0.08 & $7 \cdot 13^{\mathrm{c}}$ & 0.02 & $6 \cdot 22^{\mathrm{b}}$ & 0.06 & $5 \cdot 43^{\mathrm{a}}$ & $0 \cdot 10$ \\
\hline White muscle & 2.54 & 0.21 & $2 \cdot 67^{\mathrm{b}}$ & 0.14 & $2 \cdot 62^{b}$ & 0.06 & $2 \cdot 49^{\mathrm{b}}$ & 0.04 & $2 \cdot 17^{\mathrm{a}}$ & 0.06 \\
\hline Liver & $23 \cdot 3$ & 0.55 & $26 \cdot 7^{b}$ & 0.3 & $22 \cdot 8^{\mathrm{a}}$ & 0.6 & $35 \cdot 0^{c}$ & 0.3 & $34.9^{c}$ & 0.5 \\
\hline Mesenteric fat tissue & $84 \cdot 2$ & 8.3 & $85 \cdot 4$ & $7 \cdot 4$ & 81.5 & 4.8 & $70 \cdot 1$ & 4.0 & $65 \cdot 1$ & $3 \cdot 7$ \\
\hline \multicolumn{11}{|l|}{ Plasma index $(\mathrm{mmol} / \mathrm{l})$} \\
\hline TAG & 3.29 & 0.27 & $3.43^{\mathrm{d}}$ & 0.12 & $2 \cdot 65^{\mathrm{C}}$ & 0.04 & $2 \cdot 24^{\mathrm{b}}$ & 0.12 & $1.88^{\mathrm{a}}$ & 0.09 \\
\hline Cholesterol & 6.45 & 0.22 & $6 \cdot 73^{b}$ & 0.11 & $5 \cdot 23^{\mathrm{a}}$ & 0.21 & $6 \cdot 04^{\mathrm{a}, \mathrm{b}}$ & 0.14 & $5 \cdot 36^{\mathrm{a}}$ & 0.08 \\
\hline HDL-cholesterol & 1.04 & 0.11 & $1 \cdot 19$ & 0.09 & 0.99 & 0.08 & 1.20 & 0.09 & 1.02 & 0.07 \\
\hline LDL-cholesterol & 0.89 & 0.11 & $1 \cdot 10^{\mathrm{b}}$ & 0.09 & $0.61^{a}$ & 0.08 & $1.09^{b}$ & 0.04 & $0.81^{a, b}$ & 0.08 \\
\hline Apo A-I & 0.19 & 0.03 & $0.23^{\mathrm{b}}$ & 0.01 & $0.17^{\mathrm{a}}$ & 0.02 & $0.21^{a, b}$ & 0.01 & $0 \cdot 17^{\mathrm{a}}$ & 0.01 \\
\hline \multicolumn{3}{|c|}{ Plasma TBARS (nmol MDA/l) } & $5.39^{\mathrm{a}}$ & 0.05 & $6 \cdot 40^{\mathrm{b}}$ & 0.33 & $5 \cdot 24^{\mathrm{a}}$ & 0.28 & $5 \cdot 32^{\mathrm{a}}$ & 0.09 \\
\hline
\end{tabular}

MDA, malondialdehyde.

a,b,c,d Mean values (excluding those for the HF-diet group weeks 1-6) within a line with unlike superscript letters were significantly different $(P<0.05)$.

organs, the contents of SFA were unchanged after fenofibrate treatment, but slightly decreased after fasting. In the same organs, the contents of oleic acid and total MUFA were greater in the fenofibrate group than in the HF-diet group, but after fasting, both groups exhibited a significant decrease in MUFA contents, with the level in the fenofibrate group still greater than in the HF-diet group. Conversely, the contents of total PUFA, $n-3$ PUFA and EPA + DHA decreased significantly after fenofibrate treatment, but increased after fasting in both groups, with lower values in the fenofibrate group than in the HF-diet group. When the amounts of EPA and DHA were expressed in mg per whole organ for white muscle, liver and (a)

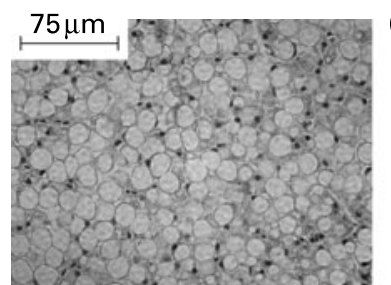

(b) $75 \mu \mathrm{m}$

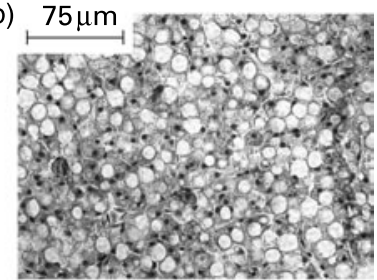

(c)

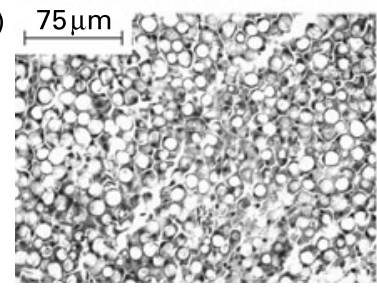

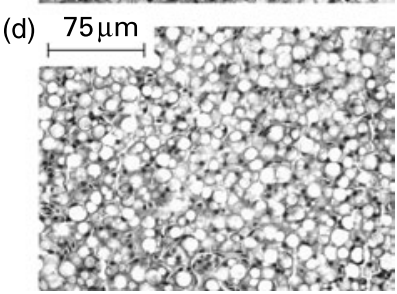

Fig. 2. Liver microstructure photographs in fish fed the high-fat (HF) diet (a), treated by fenofibrate for 2 weeks (b) and both fasted for the following 1 week, respectively (c, d). In the HF-diet group, hepatocytes appeared to be swollen with internal numerous lipid droplets of varied sizes (large round areas corresponding to fat droplets whose content was eliminated during the staining procedure), occupying most space and pushing nuclei aside to the cell periphery (a). In the fenofibrate group, swollen hepatocytes with lipid droplets of varied sizes were less numerous (b) than in the HF-diet group (a). After 1 week of fasting, the number of swollen hepatocytes seemed to increase in both groups, with more tight association than before fasting (c, d). The marked differences existing between both groups before fasting disappeared. mesenteric fat tissue, the total amount of EPA and DHA in the three organs after fenofibrate treatment was $31.7 \%$ less than for the HF-diet group. A similar drop of $34.7 \%$ was also found in both groups after fasting. Furthermore, the amounts of EPA and DHA after fasting in the organs of fish fed the HF diet were $30.3 \%$ less than before fasting, and a comparable drop of $30 \%$ was also found between before and after fasting in the fenofibrate group. However, despite the comparable total loss of EPA + DHA (about $30 \%$ ) after fasting in the three organs of each fish group, it was apparent that the loss of EPA + DHA differed between the organs. Indeed in white muscle, fenofibrate treatment caused a loss of $18 \mathrm{mg}$ $\mathrm{EPA}+\mathrm{DHA}$ by reference to the HF diet, but after 1 week of fasting, the organ lost only $2.6 \mathrm{mg}$. In the liver, the loss of $\mathrm{EPA}+\mathrm{DHA}$ due to fenofibrate and fasting was 4 or $3 \mathrm{mg}$, respectively. By contrast in mesenteric fat tissue, the loss of $\mathrm{EPA}+\mathrm{DHA}$ due to fenofibrate was $29 \mathrm{mg}$ in continuously fed fish, while the 1 week of fasting allowed the fenofibrate group to lose $24 \mathrm{mg}$ EPA + DHA. Therefore EPA + DHA would be more lowered by fenofibrate than fasting in white muscle, while fasting would be relatively more effective in mesenteric fat tissue according to the decrease in $n$-3 PUFA which partly resulted from the significant decrease of total fat (Tables 2 and 3). EPA and DHA of liver lipids were maintained at low levels, despite their high content in the dietary lipids, and had similar sensitivity to fenofibrate and fasting.

\section{Parameters related to fatty acid oxidation}

The content in mitochondrial protein per g liver was calculated from monoamine oxidase activity expressed per g liver and divided by the activity of $1 \mathrm{mg}$ mitochondrial protein. Its value was $57.6 \%$ more elevated in the fenofibrate group than in the HF-diet group (Table 7). After 1 week of fasting, the mitochondrial protein content of the liver significantly increased in the HF-diet group, but only marginally in the fenofibrate group, so that fenofibrate treatment and fasting appeared equally capable of inducing the similar increase in 
Table 4. Effect of fenofibrate treatment and fasting on fatty acid composition of total lipids (percentages of total fatty acids) in white muscle of juvenile grass carp (Ctenopharyngodon idella) fed a high-fat (HF) diet

(Mean values with their standard errors)

\begin{tabular}{|c|c|c|c|c|c|c|c|c|c|}
\hline & \multirow[b]{3}{*}{ Dietary lipids } & \multicolumn{4}{|c|}{ Continuous feeding } & \multicolumn{4}{|c|}{ Final fasting (week 9) } \\
\hline & & \multicolumn{2}{|c|}{$\begin{array}{l}\text { HF-diet group } \\
\text { (weeks 1-8) }\end{array}$} & \multicolumn{2}{|c|}{$\begin{array}{l}\text { Fenofibrate group } \\
\text { (weeks 7-8) }\end{array}$} & \multicolumn{2}{|c|}{$\begin{array}{l}\text { HF-diet group } \\
\text { (weeks 1-8) }\end{array}$} & \multicolumn{2}{|c|}{$\begin{array}{l}\text { Fenofibrate group } \\
\quad \text { (weeks } 7-8 \text { ) }\end{array}$} \\
\hline & & Mean & SEM & Mean & SEM & Mean & SEM & Mean & SEM \\
\hline $14: 0$ & 0.52 & $0.71^{\mathrm{b}}$ & 0.13 & $0.70^{b}$ & 0.03 & $0.45^{\mathrm{a}}$ & 0.05 & $0.45^{\mathrm{a}}$ & 0.03 \\
\hline $16: 0$ & $6 \cdot 40$ & $11 \cdot 3^{a, b}$ & 0.76 & $13 \cdot 1^{\mathrm{b}}$ & 0.53 & $10 \cdot 2^{a}$ & 0.45 & $13 \cdot 1^{\mathrm{b}}$ & 0.47 \\
\hline $16: 1$ & 1.93 & $3 \cdot 39$ & 0.48 & $3 \cdot 23$ & 0.44 & 1.98 & 0.09 & 2.94 & 0.37 \\
\hline $18: 0$ & $2 \cdot 01$ & $4 \cdot 87^{a}$ & 0.38 & $4.46^{a}$ & 0.35 & $5 \cdot 78^{b}$ & 0.33 & $4 \cdot 38^{a}$ & 0.31 \\
\hline $18: 1$ & $17 \cdot 7$ & $21 \cdot 4^{\mathrm{c}}$ & 0.26 & $24 \cdot 6^{d}$ & 0.20 & $14 \cdot 0^{\mathrm{a}}$ & 0.16 & $16 \cdot 7^{\mathrm{b}}$ & 0.75 \\
\hline $18: 2 n-6$ & $25 \cdot 6$ & $10 \cdot 9^{d}$ & 0.21 & $9.51^{\mathrm{c}}$ & 0.23 & $7 \cdot 21^{a}$ & 0.16 & $8 \cdot 12^{b}$ & 0.36 \\
\hline $18: 3 n-3$ & 0.42 & 0.16 & 0.02 & $0 \cdot 16$ & 0.02 & $0 \cdot 16$ & 0.05 & $0 \cdot 15$ & 0.03 \\
\hline $18: 3 n-6$ & 0.05 & 0.14 & 0.01 & 0.16 & 0.03 & 0.18 & 0.05 & 0.12 & 0.01 \\
\hline $20: 1 n-9$ & 0.61 & 0.68 & 0.10 & 0.55 & 0.28 & 0.92 & 0.56 & 0.94 & 0.23 \\
\hline $20: 2 n-6$ & $2 \cdot 35$ & 1.49 & 0.07 & 3.01 & 0.96 & 1.63 & 0.20 & 1.65 & 0.13 \\
\hline $20: 3 n-6$ & 1.44 & $1 \cdot 70$ & 0.12 & 1.45 & 0.22 & 1.49 & 0.38 & 1.64 & 0.33 \\
\hline $20: 4 n-6$ & 0.78 & $3 \cdot 20$ & 0.16 & 3.59 & 0.06 & 4.51 & 0.22 & 3.92 & 0.40 \\
\hline $20: 5 n-3$ (EPA) & 4.97 & 3.89 & 0.12 & $3 \cdot 29$ & 0.20 & $3 \cdot 81$ & 0.40 & 3.72 & 0.42 \\
\hline $22: 5 n-3$ & $2 \cdot 18$ & $2 \cdot 14^{b}$ & 0.15 & $1.48^{a}$ & 0.20 & $2 \cdot 15^{b}$ & 0.18 & $1.62^{\mathrm{a}, \mathrm{b}}$ & 0.02 \\
\hline $22: 5 n-6$ & 0.34 & $1 \cdot 50^{a}$ & 0.08 & $1.85^{a}$ & 0.05 & $3 \cdot 23^{b}$ & 0.57 & $1 \cdot 71^{a}$ & 0.12 \\
\hline $22: 6 n-3(\mathrm{DHA})$ & $24 \cdot 7$ & $22 \cdot 4^{b}$ & 0.54 & $17 \cdot 6^{\mathrm{a}}$ & $1 \cdot 20$ & $32 \cdot 0^{d}$ & 0.67 & $28 \cdot 2^{c}$ & 0.43 \\
\hline$\Sigma S F A$ & 8.93 & $16 \cdot 9$ & 0.65 & $18 \cdot 2$ & 0.24 & $16 \cdot 5$ & 0.72 & $17 \cdot 9$ & 0.39 \\
\hline$\Sigma$ MUFA & $20 \cdot 2$ & $25 \cdot 5^{c}$ & 0.62 & $28.4^{d}$ & 0.44 & $16 \cdot 9^{a}$ & 0.80 & $20 \cdot 5^{b}$ & 0.89 \\
\hline$\Sigma P U F A$ & $62 \cdot 8$ & $47 \cdot 5^{b}$ & 0.53 & $42 \cdot 1^{a}$ & 0.95 & $56 \cdot 4^{d}$ & 0.15 & $50 \cdot 9^{C}$ & 1.30 \\
\hline$\Sigma n-6$ PUFA & $30 \cdot 5$ & $18 \cdot 9$ & 0.30 & $19 \cdot 6$ & 0.63 & $18 \cdot 3$ & 0.94 & $17 \cdot 2$ & 0.59 \\
\hline$\Sigma n-3$ PUFA & $32 \cdot 3$ & $28 \cdot 5^{b}$ & 0.44 & $22 \cdot 5^{a}$ & 1.52 & $38 \cdot 1^{d}$ & 1.09 & $33 \cdot 7^{c}$ & 0.76 \\
\hline $\mathrm{EPA}+\mathrm{DHA}$ & 29.7 & $26 \cdot 2^{b}$ & 0.56 & $20 \cdot 9^{a}$ & 1.36 & $35 \cdot 8^{d}$ & 1.01 & $31.9^{c}$ & 0.75 \\
\hline ¿MUFA (mg/org & & $73 \cdot 2^{b}$ & 2.47 & $78 \cdot 7^{\mathrm{b}}$ & $2 \cdot 15$ & $34 \cdot 3^{a}$ & 1.93 & $33 \cdot 4^{a}$ & 2.04 \\
\hline $\mathrm{EPA}+\mathrm{DHA}(\mathrm{m}$ & & $75 \cdot 2^{b}$ & 3.48 & $57 \cdot 9^{a}$ & $5 \cdot 34$ & $72 \cdot 6^{\mathrm{b}}$ & 4.03 & $52 \cdot 0^{\mathrm{a}}$ & $3 \cdot 19$ \\
\hline
\end{tabular}

a,b,c,d Mean values (excluding the dietary lipids values) within a line with unlike superscript letters were significantly different $(P<0.05)$.

* $\Sigma$ MUFA or EPA + DHA amount per whole organ $=$ EPA + DHA or $\Sigma$ MUFA composition (in weight $\%$ of total lipids) $\times$ total lipid content (in weight $\%$ of organ) $\times$ organ weight (g).

liver mitochondrial protein per g liver. Among parameters related to mitochondrial FA oxidation, carnitine-dependent palmitate oxidation rates expressed per g liver were significantly greater in the fenofibrate group than in the HF-diet group only when calculated from results obtained from crude liver homogenates (Table 7). Indeed, when activity rates were calculated from mitochondrial fractions (excluding the other parts of cells), there was no more difference between the HF-diet and fenofibrate groups. After fasting, activity rates of carnitine-dependent palmitate oxidation in both groups calculated from homogenates and isolated mitochondria were significantly increased, but with lower values in the fenofibrate group than in the HF-diet group. The activity rate of CPT I, a key enzyme of the mitochondrial FA oxidation pathway, when expressed per g liver, was slightly greater in the fenofibrate group than in the HF-diet group. This activity significantly increased during the fasting period in both groups, but with relatively less extent in the fenofibrate group.

As regards catalase, a peroxisomal marker enzyme, its activity expressed per $g$ liver was significantly greater in the fenofibrate group than in the HF-diet group. However, after fasting, the peroxisomal marker activity only exhibited slightly higher values in the HF-diet group, and the difference between the two groups before fasting disappeared (Table 7). Peroxisomal FA oxidation does not require carnitine, and its activity rates measured with palmitate were significantly more elevated in the fenofibrate group than in the HF-diet group. After fasting, these activity rates were increased in both groups, but with comparable levels (Table 7). The activity rate of the peroxisomal FA-oxidising system, which is a key sequence of the whole peroxisomal FA oxidation pathway, was nearly $20 \%$ increased after fenofibrate treatment. After fasting, this activity was significantly lowered in both groups, but still with a slightly greater value in the fenofibrate group.

\section{Discussion}

\section{Hyperlipidaemia and herbivorous grass carp}

Chronic hyperlipidaemia represents a major risk of CVD in humans. It may arise from inborn defects, but increasingly results from unbalanced dietary habits with excess fat-rich food consumption ${ }^{(45,46)}$. Hyperlipidaemia is also easily induced in animal models fed HF diets ${ }^{(47,48)}$. This blood symptom may regress in humans and animals via fibrate administration or dietary regimens often based on the reduction of food intake. Comparing these treatments is difficult because of side effects met with fibrates in rodents through apparent liver peroxisomal proliferation, which does not occur in humans, and with partial fasting in humans often associated with sudden contrary reactions. Carnivorous fish fed HF diets were described to exhibit hyperlipidaemia-associated alterations similar to those reported in hum-ans ${ }^{(49-52)}$. The advantage of using the herbivorous grass carp as a model is that this fish is able to support relatively 
Table 5. Effect of fenofibrate treatment and fasting on fatty acid composition of total lipids (percentages of total fatty acids) in liver of juvenile grass carp (Ctenopharyngodon idella) fed a high-fat (HF) diet

(Mean values with their standard errors)

\begin{tabular}{|c|c|c|c|c|c|c|c|c|c|}
\hline & \multirow[b]{3}{*}{ Dietary lipids } & \multicolumn{4}{|c|}{ Continuous feeding } & \multicolumn{4}{|c|}{ Final fasting (week 9) } \\
\hline & & \multicolumn{2}{|c|}{$\begin{array}{l}\text { HF-diet group } \\
\text { (weeks 1-8) }\end{array}$} & \multicolumn{2}{|c|}{$\begin{array}{l}\text { Fenofibrate group } \\
\text { (weeks } 7-8 \text { ) }\end{array}$} & \multicolumn{2}{|c|}{$\begin{array}{l}\text { HF-diet group } \\
\text { (weeks 1-8) }\end{array}$} & \multicolumn{2}{|c|}{$\begin{array}{l}\text { Fenofibrate group } \\
\quad \text { (weeks 7-8) }\end{array}$} \\
\hline & & Mean & SEM & Mean & SEM & Mean & SEM & Mean & SEM \\
\hline $14: 0$ & 0.52 & $1 \cdot 12$ & 0.12 & $1 \cdot 13$ & 0.12 & 0.93 & 0.08 & 0.88 & $0 \cdot 19$ \\
\hline $16: 0$ & $6 \cdot 40$ & $16 \cdot 4$ & 0.37 & $16 \cdot 6$ & $1 \cdot 10$ & $14 \cdot 3$ & 0.83 & $16 \cdot 0$ & 0.98 \\
\hline $16: 1$ & 1.93 & $5 \cdot 15$ & $0 \cdot 18$ & $5 \cdot 51$ & 0.63 & 4.54 & 0.27 & $5 \cdot 21$ & 0.21 \\
\hline $18: 0$ & 2.01 & 8.91 & 0.07 & 9.07 & 0.84 & 8.38 & $0 \cdot 13$ & $7 \cdot 29$ & 0.05 \\
\hline $18: 1$ & $17 \cdot 7$ & $39 \cdot 6^{\mathrm{b}}$ & 0.43 & $42 \cdot 3^{c}$ & 1.02 & $36 \cdot 0^{\mathrm{a}}$ & 1.01 & $38 \cdot 1^{\mathrm{a}, \mathrm{b}}$ & 0.62 \\
\hline $18: 2 n-6$ & $25 \cdot 6$ & $2 \cdot 87^{\mathrm{a}}$ & 0.23 & $2.95^{\mathrm{a}}$ & 0.62 & $3.83^{\mathrm{a}, \mathrm{b}}$ & 0.06 & $4.54^{\mathrm{c}}$ & 0.27 \\
\hline $18: 3 n-3$ & 0.42 & $0.15^{\mathrm{b}}$ & 0.01 & $0.15^{\mathrm{b}}$ & 0.01 & $0 \cdot 11^{b}$ & 0.02 & $0.06^{\mathrm{a}}$ & 0.01 \\
\hline $18: 3 n-6$ & 0.05 & $0.13^{\mathrm{b}}$ & 0.01 & $0 \cdot 11^{a, b}$ & 0.02 & $0.11^{\mathrm{b}}$ & 0.01 & $0.06^{\mathrm{a}}$ & 0.02 \\
\hline $20: 1 n-9$ & 0.61 & $1 \cdot 14$ & $0 \cdot 10$ & 0.91 & 0.09 & 1.45 & 0.09 & 0.88 & 0.33 \\
\hline $20: 2 n-6$ & 2.35 & 2.48 & 0.24 & 1.96 & $0 \cdot 10$ & $2 \cdot 89$ & 0.11 & 3.74 & 0.73 \\
\hline $20: 3 n-6$ & 1.44 & 0.89 & 0.09 & 0.68 & 0.08 & 1.77 & 0.56 & 0.64 & $0 \cdot 19$ \\
\hline $20: 4 n-6$ & 0.78 & 0.85 & $0 \cdot 10$ & 0.79 & 0.08 & 0.78 & 0.42 & 0.61 & $0 \cdot 18$ \\
\hline $20: 5 n-3$ (EPA) & 4.97 & 1.21 & 0.15 & 1.00 & $0 \cdot 10$ & 1.40 & 0.25 & 1.29 & 0.29 \\
\hline $22: 5 n-3$ & $2 \cdot 18$ & 0.83 & 0.05 & 0.48 & 0.14 & 0.95 & 0.07 & 0.72 & 0.35 \\
\hline $22: 5 n-6$ & 0.34 & 0.30 & 0.04 & 0.20 & 0.04 & 0.28 & 0.04 & 0.27 & 0.01 \\
\hline $22: 6 n-3(\mathrm{DHA})$ & $24 \cdot 7$ & $5 \cdot 64^{b}$ & 0.21 & $3.95^{a}$ & 0.20 & $7 \cdot 04^{c}$ & 0.55 & $3.57^{\mathrm{a}}$ & 0.35 \\
\hline ¿SFA & 8.93 & $26 \cdot 4^{b, c}$ & 0.55 & $26 \cdot 8^{\mathrm{c}}$ & 0.50 & $23 \cdot 6^{\mathrm{a}}$ & 1.03 & $24 \cdot 2^{a, b}$ & 0.88 \\
\hline ¿MUFA & $20 \cdot 2$ & $45 \cdot 9^{b}$ & 0.36 & $48 \cdot 8^{\mathrm{c}}$ & 1.06 & $42 \cdot 0^{\mathrm{a}}$ & 0.88 & $44 \cdot 2^{a, b}$ & 0.77 \\
\hline SPUFA & $62 \cdot 8$ & $15 \cdot 4^{\mathrm{b}}$ & 0.83 & $12 \cdot 3^{\mathrm{a}}$ & 1.01 & $19 \cdot 2^{c}$ & 1.04 & $15 \cdot 5^{\mathrm{b}}$ & 0.59 \\
\hline$\sum n-6$ PUFA & 30.5 & $7.52^{\mathrm{a}}$ & 0.49 & $6 \cdot 68^{\mathrm{a}}$ & 0.84 & $9 \cdot 68^{b}$ & 0.33 & $9 \cdot 87^{b}$ & 0.89 \\
\hline$\Sigma n-3$ PUFA & $32 \cdot 3$ & $7 \cdot 83^{\mathrm{b}}$ & 0.35 & $5.58^{\mathrm{a}}$ & 0.43 & $9.49^{\mathrm{b}}$ & 0.72 & $5 \cdot 65^{\mathrm{a}}$ & 0.89 \\
\hline $\mathrm{EPA}+\mathrm{DHA}$ & 29.7 & $6 \cdot 9^{\mathrm{b}}$ & 0.35 & $4.95^{a}$ & 0.29 & $8.44^{\mathrm{b}}$ & 0.64 & $4 \cdot 86^{\mathrm{a}}$ & 0.63 \\
\hline \multicolumn{2}{|c|}{ ¿MUFA (mg/organ)* } & $67 \cdot 9^{\mathrm{c}}$ & 0.64 & $58 \cdot 5^{\mathrm{b}}$ & 1.33 & $35.4^{\mathrm{a}}$ & 0.89 & $33 \cdot 6^{\mathrm{a}}$ & 0.65 \\
\hline \multicolumn{2}{|c|}{$\mathrm{EPA}+\mathrm{DHA}(\mathrm{mg} / \text { organ) })^{*}$} & $10 \cdot 2^{\mathrm{d}}$ & 0.94 & $5.93^{b}$ & 0.67 & $7 \cdot 12^{c}$ & 0.28 & $3 \cdot 70^{\mathrm{a}}$ & 0.54 \\
\hline
\end{tabular}

a,b,c,d Mean values (excluding the dietary lipids values) within a line with unlike superscript letters were significantly different $(P<0.05)$.

* $\Sigma$ MUFA or EPA + DHA amount per whole organ $=$ EPA + DHA or $\Sigma$ MUFA composition (in weight $\%$ of total lipids) $\times$ total lipid content (in weight $\%$ of organ) $\times$ organ weight (g).

long times of fasting and to be sensitive to dietary lipids ${ }^{(24-26)}$. Previous studies showed that, in normally fed grass carp, plasma TAG, cholesterol, HDL-C and LDL-C were nearly 1.5, 3, 0.4 and $0.3 \mathrm{mmol} / \mathrm{l}$, respectively, but in the present study with fish fed an HF diet, the corresponding values were $3 \cdot 5,6 \cdot 7$, $1 \cdot 2$ and $1.1 \mathrm{mmol} / \mathrm{l}$, respectively. Consequently, grass carp is capable of developing hyperlipidaemia, and its biological reactions to fibrates (here used as fenofibrate) and to fasting are discussed below.

\section{Hypolipidaemic effects of fenofibrate and fasting}

The fenofibrate-induced reduction of plasma TAG and cholesterol has been suggested to maximally result from alteration of liver lipoprotein synthesis and secretion, inhibition of cholesterol synthesis and increased FA oxidation via PPAR in rodents and hyperlipidaemic patients ${ }^{(6-12)}$. The present study shows that the hypolipidaemic effects of fenofibrate also occur in grass carp. We observed that plasma TAG, cholesterol and LDL-C decreased after fenofibrate treatment, but also with a decrease in HDL-C and apo A-I. Some studies have shown that low concentrations of HDL-C predict an increased CHD risk at any LDL-C level ${ }^{(53,54)}$, but fenofibrate could produce a significant increase in HDL-C in patients ${ }^{(46)}$. Contrary to humans, fibrate-treated rats, mice and hamsters exhibited decreased plasma HDL-C and liver apo A-I mRNA levels ${ }^{(6,9,55)}$. The divergent effects of fenofibrate in rodents and fish $v$. humans suggest that the sensitivity of
PPAR to fibrate and the sequence of the involved peroxisome-proliferator responsive element of apo A-I markedly differ in rodents and fish compared with humans. Indeed, the promoters of the apo A-I gene have been shown to possess distinct sequences in rodents and humans ${ }^{(56)}$. Compared with fenofibrate, fasting resulted in the reduction of plasma TAG, but not of cholesterol. A similar decrease in plasma TAG during starvation was also reported in some carnivorous fish ${ }^{(57,58)}$, but this decrease was associated with an increase in cholesterol. In humans and animal models, similar conflicting data regarding the effects of fasting on plasma TAG and cholesterol have also been found ${ }^{(17-21)}$. These inconsistencies may originate from sex, age, obesity, hyperlipidaemia, health state, medication, diets and/or physical activity during fasting ${ }^{(17)}$. Interestingly, semi-starvation of $6 \mathrm{~d}$ did not affect serum TAG and cholesterol in non-obese men and women, but lowered TAG and did not change cholesterol in obese individuals ${ }^{(19)}$. This latter situation was very similar to the results of grass carp in the present study whose excess body fat was due to an HF feeding.

\section{Lipid deposition and mobilisation}

Grass carp fed HF diets were previously shown to easily accumulate body fats, especially when ingested lipids were rich in PUFA which exerted deleterious effects ${ }^{(24-26)}$. In the present study, the HF $(8 \%)$ diet which also contained high PUFA (62.8\% total FA) was capable of markedly increasing 
Table 6. Effect of fenofibrate treatment and fasting on fatty acid composition (percentages of total fatty acids) of mesenteric fat tissue in juvenile grass carp (Ctenopharyngodon idella) fed a high-fat (HF) diet

(Mean values with their standard errors)

\begin{tabular}{|c|c|c|c|c|c|c|c|c|c|}
\hline & \multirow[b]{3}{*}{ Dietary lipids } & \multicolumn{4}{|c|}{ Continuous feeding } & \multicolumn{4}{|c|}{ Final fasting (week 9) } \\
\hline & & \multicolumn{2}{|c|}{$\begin{array}{l}\text { HF-diet group } \\
\text { (weeks 1-8) }\end{array}$} & \multicolumn{2}{|c|}{$\begin{array}{l}\text { Fenofibrate group } \\
\quad \text { (weeks } 7-8 \text { ) }\end{array}$} & \multicolumn{2}{|c|}{$\begin{array}{l}\text { HF-diet group } \\
\text { (weeks 1-8) }\end{array}$} & \multicolumn{2}{|c|}{$\begin{array}{l}\text { Fenofibrate group } \\
\quad \text { (weeks } 7-8 \text { ) }\end{array}$} \\
\hline & & Mean & SEM & Mean & SEM & Mean & SEM & Mean & SEM \\
\hline $14: 0$ & 0.52 & 1.02 & 0.05 & 0.83 & 0.05 & 0.94 & 0.06 & 0.92 & $0 \cdot 10$ \\
\hline $16: 0$ & $6 \cdot 40$ & $12 \cdot 2$ & 0.26 & 10.9 & 0.68 & $10 \cdot 3$ & $0 \cdot 80$ & $11 \cdot 2$ & 0.53 \\
\hline $16: 1$ & 1.93 & $5 \cdot 18$ & 0.09 & 4.56 & $0 \cdot 21$ & 4.92 & $0 \cdot 26$ & $5 \cdot 19$ & 0.43 \\
\hline $18: 0$ & 2.01 & 3.53 & 0.20 & 3.44 & $0 \cdot 13$ & $3 \cdot 18$ & 0.33 & $3 \cdot 27$ & 0.20 \\
\hline $18: 1$ & $17 \cdot 7$ & $29 \cdot 1$ & 0.36 & 30.9 & 0.25 & $29 \cdot 7$ & 0.23 & $30 \cdot 3$ & $1 \cdot 27$ \\
\hline $18: 2 n-6$ & $25 \cdot 6$ & $14 \cdot 4$ & 0.42 & $15 \cdot 4$ & $0 \cdot 18$ & $15 \cdot 9$ & 0.83 & $14 \cdot 3$ & 0.55 \\
\hline $18: 3 n-3$ & 0.42 & 0.12 & 0.01 & 0.13 & 0.02 & 0.12 & 0.02 & 0.12 & 0.02 \\
\hline $18: 3 n-6$ & 0.05 & 0.12 & 0.01 & 0.15 & 0.01 & 0.16 & 0.02 & 0.15 & 0.02 \\
\hline $20: 1 n-9$ & 0.61 & 0.96 & 0.03 & $1 \cdot 23$ & 0.26 & 1.04 & 0.04 & $1 \cdot 13$ & 0.10 \\
\hline $20: 2 n-6$ & $2 \cdot 35$ & 2.56 & 0.26 & 2.09 & 0.22 & 2.52 & $0 \cdot 12$ & $2 \cdot 49$ & 0.09 \\
\hline $20: 3 n-6$ & 1.44 & 1.00 & 0.01 & 1.09 & 0.03 & $1 \cdot 24$ & 0.03 & 1.47 & 0.34 \\
\hline $20: 4 n-6$ & 0.78 & 0.89 & 0.03 & 0.78 & 0.03 & 0.99 & 0.02 & 0.92 & 0.08 \\
\hline $20: 5 n-3$ (EPA) & 4.97 & $2 \cdot 47$ & 0.08 & $2 \cdot 31$ & 0.04 & $2 \cdot 64$ & $0 \cdot 12$ & $2 \cdot 80$ & 0.07 \\
\hline $22: 5 n-3$ & $2 \cdot 18$ & $2 \cdot 18$ & 0.18 & $2 \cdot 21$ & 0.17 & $2 \cdot 21$ & 0.06 & $2 \cdot 14$ & $0 \cdot 10$ \\
\hline $22: 5 n-6$ & 0.34 & 0.38 & 0.03 & 0.38 & 0.03 & 0.46 & 0.04 & 0.45 & 0.05 \\
\hline $22: 6 n-3(\mathrm{DHA})$ & $24 \cdot 7$ & $13 \cdot 6$ & 0.30 & $12 \cdot 8$ & 0.19 & $13 \cdot 2$ & $0 \cdot 20$ & $12 \cdot 6$ & 0.08 \\
\hline$\Sigma S F A$ & 8.93 & $16 \cdot 7$ & 0.40 & $15 \cdot 2$ & 0.79 & $16 \cdot 5$ & 0.72 & $17 \cdot 9$ & 0.39 \\
\hline$\Sigma$ MUFA & $20 \cdot 2$ & $35 \cdot 2$ & 0.41 & $36 \cdot 7$ & 0.09 & $35 \cdot 7$ & 0.09 & $36 \cdot 6$ & 0.89 \\
\hline$\Sigma$ PUFA & $62 \cdot 8$ & $37 \cdot 7$ & 0.90 & 37.4 & 0.28 & 39.5 & 0.90 & 37.5 & 0.63 \\
\hline$\Sigma n-6$ PUFA & 30.5 & $19 \cdot 3$ & 0.58 & $19 \cdot 9$ & 0.08 & $21 \cdot 3$ & 0.84 & $19 \cdot 8$ & 0.48 \\
\hline$\Sigma n-3$ PUFA & $32 \cdot 3$ & $18 \cdot 4$ & 0.32 & $17 \cdot 5$ & 0.28 & $18 \cdot 2$ & 0.26 & $17 \cdot 7$ & $0 \cdot 16$ \\
\hline $\mathrm{EPA}+\mathrm{DHA}$ & $29 \cdot 7$ & $16 \cdot 1$ & 0.27 & $15 \cdot 1$ & $0 \cdot 15$ & $15 \cdot 8$ & 0.31 & $15 \cdot 4$ & 0.07 \\
\hline \multicolumn{2}{|c|}{ ¿MUFA (mg/organ)* } & $160 \cdot 3^{d}$ & $4 \cdot 21$ & $109 \cdot 7^{c}$ & $3 \cdot 27$ & $70 \cdot 6^{\mathrm{b}}$ & $2 \cdot 04$ & $48 \cdot 4^{a}$ & 2.47 \\
\hline \multicolumn{2}{|c|}{$\mathrm{EPA}+\mathrm{DHA}$ (mg/organ)* } & $73 \cdot 5^{d}$ & $4 \cdot 33$ & $44 \cdot 7^{\mathrm{C}}$ & $3 \cdot 76$ & $30 \cdot 9^{b}$ & $3 \cdot 11$ & $20 \cdot 3^{a}$ & $4 \cdot 19$ \\
\hline
\end{tabular}

a,b,c,d Mean values (excluding the dietary lipids values) within a line with unlike superscript letters were significantly different $(P<0.05)$

${ }^{*} \Sigma$ MUFA or EPA + DHA amount per whole organ $=$ EPA + DHA or $\Sigma$ MUFA composition (in weight $\%$ of total lipids) $\times$ total lipid content (in weight $\%$ of organ) $\times$ organ weight (g).

body lipids. In liver cells, fat accumulation was developed with the numerous large lipid droplets filling up nearly all the cytoplasmic volume. Total hepatic lipid content exceeded $20 \%$ in the present study, but normally it is maintained below $15 \%$ in the liver. Further, mesenteric fat tissue that normally represents less than $2 \%$ of $\mathrm{BW}$, reached $3.28 \%$ in the fish fed the HF diet. With the grass carp model, fenofibrate treatment succeeded in significantly reducing whole-body and liver lipids, as well as mesenteric fat tissue mass. Such a reduction should imply an increased use of fat to meet energetic requirements. These requirements are metabolically low in mesenteric fat tissue, compared with those in the liver and muscles; the loss of weight of fat tissues with fenofibrate therefore suggests that the large amounts of NEFA released from the fat stores were used in energy-demanding organs. The liver appeared to be particularly sensitive to fenofibrate because of its capacity to reduce size and number of fat droplets accumulated within hepatocytes, and also to deal with NEFA of peripheral origin. This efficiency has also been recovered in diet-induced obese rats ${ }^{(13)}$ and in rainbow trout $^{(23)}$. Fenofibrate and other fibrates have been demonstrated to alter hepatic FA metabolism ${ }^{(59)}$ via induction of FA oxidation-related enzymes, such as mitochondrial CPT I, peroxisomal acyl-CoA oxidase and lipoprotein lipase, through PPAR $\alpha$ activation. This suggests that lipid deposition in the grass carp model was counterbalanced by higher levels of FA oxidation through specific fibrate effects. After fasting, lipids of the whole body, mesenteric fat tissue and white muscle were decreased, but, surprisingly, lipids of the liver were increased as far as to trigger hepatic steatosis. These data differ from those reported in most fish, in which liver lipids tended to be used first ${ }^{(60)}$, but resemble those described in PPAR $\alpha$-null mice ${ }^{(14)}$, shrews (Suncus murinus) ${ }^{(16)}$ and rats ${ }^{(61)}$ with liver lipid accumulation after fasting. Indeed ligands of PPAR $\alpha$ as fibrates are known to up-regulate, as mentioned above, FA oxidation-related enzymes ${ }^{(62)}$, while those of PPAR $y$ as thiazolidinediones result in stimulating the esterification levels in adipose tissue ${ }^{(63)}$. It was effectively shown that PPAR $\gamma$-null rats were unable to preserve their fat stores $^{(64)}$. In this context, the fact that PPAR $\gamma$ is down-regulated by fasting as well as in insulin-deficient diabetes ${ }^{(65)}$ would explain in our fish model, associated with the need of energetic substrates, the marked loss of weight of mesenteric fat tissue observed after fasting. The absence of insulin secretion during this period should result in an intense peripheral lipolysis followed by a likely increased uptake of NEFA by liver cells. This would saturate the hepatic FA oxidation capacities, with concomitant esterification of excess FA into TAG, as clearly shown in Table 3. Previous studies have also shown that impaired hepatic FA oxidation may occur concurrently with excess esterification reactions, as developed by the hepatic steatosis setup ${ }^{(25)}$. Further, food deprivation could be even still more deleterious in steatotic hepatocytes ${ }^{(66)}$.

\section{Fatty acid composition in tissues}

The total amounts of EPA and DHA in the lipids of liver, white muscle and mesenteric fat tissue were 42,23 and $40 \%$, 
Table 7. Effect of fenofibrate treatment and fasting on parameters related to mitochondrial and peroxisomal fatty acid oxidation in the liver of juvenile grass carp (Ctenopharyngodon idella) fed a high-fat (HF) diet

(Mean values with their standard errors)

\begin{tabular}{|c|c|c|c|c|c|c|c|c|}
\hline & \multicolumn{4}{|c|}{ Continuous feeding } & \multicolumn{4}{|c|}{ Final fasting (week 9) } \\
\hline & \multicolumn{2}{|c|}{$\begin{array}{l}\text { HF-diet group } \\
\text { (weeks } 1-8 \text { ) }\end{array}$} & \multicolumn{2}{|c|}{$\begin{array}{l}\text { Fenofibrate group } \\
\quad \text { (weeks 7-8) }\end{array}$} & \multicolumn{2}{|c|}{$\begin{array}{l}\text { HF-diet group } \\
\text { (weeks 1-8) }\end{array}$} & \multicolumn{2}{|c|}{$\begin{array}{l}\text { Fenofibrate group } \\
\quad \text { (weeks } 7-8 \text { ) }\end{array}$} \\
\hline & Mean & SEM & Mean & SEM & Mean & SEM & Mean & SEM \\
\hline \multicolumn{9}{|l|}{ Monoamine oxidase activity (mitochondrial marker enzyme) } \\
\hline In tissue homogenates (nmol/min per g wet liver) & $52 \cdot 1^{\mathrm{a}}$ & 1.8 & $103 \cdot 7^{b}$ & 4.2 & $93.8^{\mathrm{b}}$ & $5 \cdot 8$ & $102 \cdot 6^{\mathrm{b}}$ & 5.8 \\
\hline In mitochondrial fractions ( $\mathrm{nmol} / \mathrm{min}$ per $\mathrm{mg}$ protein) & $8 \cdot 1$ & $1 \cdot 1$ & $9 \cdot 7$ & 0.2 & 8.4 & 0.2 & $9 \cdot 1$ & 0.5 \\
\hline Mitochondria content (mg protein per g wet tissue) & 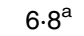 & 1.3 & $10 \cdot 7^{\mathrm{b}}$ & 0.5 & $11 \cdot 2^{\mathrm{b}}$ & 0.9 & $11 \cdot 3^{\mathrm{b}}$ & 0.6 \\
\hline \multicolumn{9}{|l|}{ Mitochondria-related palmitate oxidation } \\
\hline $\begin{array}{l}\text { Carnitine-dependent palmitate oxidation } \\
\text { (nmol/min per g wet liver) calculated } \\
\text { from tissue homogenates }\end{array}$ & $62 \cdot 5^{\mathrm{a}}$ & 0.5 & $75 \cdot 8^{\mathrm{b}}$ & $1 \cdot 1$ & $126 \cdot 9^{c}$ & $9 \cdot 1$ & $110 \cdot 8^{c}$ & $8 \cdot 1$ \\
\hline $\begin{array}{l}\text { Carnitine palmitoyltransferase I (nmol/min per g wet liver) })^{\star} \\
\text { measured from isolated mitochondrial fractions }\end{array}$ & $38 \cdot 5^{\mathrm{a}}$ & $4 \cdot 3$ & $44 \cdot 8^{\mathrm{a}}$ & $4 \cdot 3$ & $123 \cdot 1^{c}$ & $6 \cdot 0$ & $95 \cdot 3^{b}$ & $11 \cdot 2$ \\
\hline \multicolumn{9}{|l|}{ Peroxisomal marker enzyme } \\
\hline Catalase activity (mol/min per $\mathrm{g}$ wet liver) & $27 \cdot 6^{\mathrm{a}}$ & 1.0 & $32 \cdot 8^{\mathrm{b}}$ & 0.5 & $30 \cdot 2^{a, b}$ & 0.8 & $31 \cdot 2^{a, b}$ & 1.9 \\
\hline \multicolumn{9}{|l|}{ Peroxisome-related palmitate oxidation } \\
\hline $\begin{array}{l}\text { Carnitine-independent palmitate oxidation } \\
\text { in tissue homogenates (nmol/min per g wet liver) }\end{array}$ & $3.8^{\mathrm{a}}$ & 0.4 & $5 \cdot 3^{b}$ & 0.4 & $5 \cdot 5^{\mathrm{b}}$ & 0.3 & $6 \cdot 1^{b}$ & $1 \cdot 0$ \\
\hline $\begin{array}{l}\text { Peroxisomal fatty acid oxidising system } \\
\text { (nmol/min per } \mathrm{g} \text { wet liver) }\end{array}$ & $84.9^{b}$ & $2 \cdot 7$ & $102 \cdot 0^{\mathrm{C}}$ & 3.5 & $66 \cdot 4^{\mathrm{a}}$ & $5 \cdot 3$ & $70 \cdot 9^{\mathrm{a}}$ & $2 \cdot 4$ \\
\hline
\end{tabular}

a,b,c Mean values within a line with unlike superscript letters were significantly different $(P<0.05)$.

${ }^{\star}$ Calculated from activities in mitochondrial fractions ( $\mathrm{nmol} / \mathrm{min}$ per $\mathrm{mg}$ protein) multiplied by corresponding mitochondrial protein contents per $\mathrm{g}$ liver.

respectively, less in the fenofibrate group than in the HF-diet group (Tables 4-6). This meant that fenofibrate was more effective at decreasing the contents of $n-3$ highly unsaturated FA in the liver and mesenteric fat tissue than in white muscle. Further, the composition of EPA + DHA (expressed as \% of total FA) in the HF-diet $v$. fenofibrate groups in liver, muscle and fat tissue was 6.9 v. $4.95,26 \cdot 2$ v. 20.9 and $16 \cdot 1$ v. $15 \cdot 1$, respectively. This implies that the natural mechanisms of lowing $n$-3 highly unsaturated FA were more active in the liver and fat tissue than in white muscle, and these organ difference did not alter by finofibrate treatment. Data obtained in rodents showed that the levels of FA oxidation are markedly greater in the liver than in muscle, and that DHA is nearly exclusively $\beta$-oxidised within peroxisomes, and EPA within both mitochondria and peroxisomes ${ }^{(67,68)}$. Further, fenofibrate was demonstrated to up-regulate mitochondrial and peroxisomal FA oxidation activities via PPAR $\alpha^{(9-12)}$. These data obtained in rodents appeared to meet ours in herbivorous fish because liver activities of grass carp were naturally capable of strongly reducing EPA + DHA, relative to white muscle, and fenofibrate treatment amplified this capability to reduce more $n-3$ highly unsaturated FA. These results also support those obtained in carnivorous rainbow trout ${ }^{(23)}$. On the other hand, 1 week of fasting did not change the amounts of EPA + DHA in white muscles, but decreased those in the liver and mesenteric fat tissue by 30 and $58 \%$, respectively. Meanwhile the amounts of MUFA lost after fasting in the liver, white muscle and mesenteric fat tissue were 50,54 and $56 \%$, respectively. These results meet the results reported in other fish, such as channel catfish $^{(69)}$ and red tilapia ${ }^{(60)}$. Further, the amounts of EPA + DHA lost by the liver + white muscle after fasting or fenofibrate treatment were 5.6 or $22 \mathrm{mg}$, respectively, while the amounts of MUFA lost under the same conditions were 71 and $4 \mathrm{mg}$, respectively. The inverse relationship of $n-3$ PUFA $v$. MUFA contents first between the liver and white muscle, and second between fasting and fenofibrate treatment may be explained through: (a) the FA oxidation specificity of peroxisomes mentioned above, compared with that of mitochondria in which MUFA from 16 to 18 carbons are among the best FA oxidation substrates ${ }^{(70)}$; (b) the relatively high mitochondria content of muscle cells compared with that of hepatocytes that also contain non-negligible amounts of peroxisomes ${ }^{(71,72)}$; (c) the much higher capacity of peroxisome proliferation in liver cells than in muscle cells after fibrate treatment ${ }^{(71,72)}$. Since fish compared with mammals have lower capacities to synthesise EPA and DHA from linolenic acid ${ }^{(73)}$, these $n$-3 PUFA were relatively preserved in tissues, more particularly in muscles. In fasting grass carp, the peroxisomal FA oxidation pathway should be weakly active. Inversely, the apparent decrease in MUFA after fasting also suggested that the mitochondrial FA oxidation pathway was significantly activated. These data prompted us to further investigate some FA oxidation-related activities in the liver.

\section{Parameters related to hepatic fatty acid oxidation}

Comparing lipid metabolism between mammals and fish in similar experimental designs, some differences have been observed. For example in mammals, fenofibrate has been shown to induce the enlargement of the liver via anti-apoptotic mechanisms ${ }^{(74)}$ and to increase the number and size of mitochondria and peroxisomes in liver cells ${ }^{(75,76)}$. The same treatment applied to grass carp did not change the weight of liver, but, however, increased the mitochondria content in this tissue, as has been previously observed in rainbow trout ${ }^{(23)}$. 
Although CPT I activities in isolated mitochondria were slightly lowered after fenofibrate treatment, the concomitant greater contents of mitochondria in the liver led to a marginal increase of CPT I activity expressed per $g$ tissue, and this partly explained the increased activities of greater palmitate oxidation using liver homogenates in the fenofibrate group (Table 7). Indeed, previous studies reported that fenofibrate up-regulated mitochondrial activities via the nuclear DNA, and also via the mitochondrial genome, which would increase the liver content of mitochondria ${ }^{(13,15)}$. The increased activity of catalase, which is a peroxisome marker, was associated with a significantly increased activity rate of the peroxisomal FA-oxidising system and with a significantly increased carnitine-independent palmitate oxidation rate in the liver of fish treated with fenofibrate (Table 7). This strongly suggests that both the peroxisome induction by fenofibrate in the liver and the specificity of peroxisomal oxidation towards very-long-chain FA were mainly responsible for the marked reduction of EPA and DHA in the tissues studied.

In food-deprived rodents, PPAR $\alpha$ was found to play a role in the regulation of mitochondrial and peroxisomal FA oxidation, which suggests that PPAR $\alpha$ was involved in the transcriptional response to fasting ${ }^{(14)}$. This was supported by the fact that, during the fasting period, PUFA released from peripheral tissues were potential ligands for PPAR $\alpha$ in liver cells ${ }^{(77)}$, but also would imply that fenofibrate and fasting employed the same regulatory pathways ${ }^{(15)}$. This assertion was not fully satisfied in grass carp with the differences mentioned above between fasting and fenofibrate treatment, liver and muscle FA metabolism, and disappearance of MUFA $v$. EPA + DHA content. Further, starvation of Fischer-344 rats for $5 \mathrm{~d}$ was found to result in a $2 \cdot 1$-fold increase in liver peroxisomal $\beta$-oxidation ${ }^{(77)}$, while another study reported that the activity of peroxisomal fatty acyl-CoA oxidase was $73 \%$ lower in the liver of fasted rats ${ }^{(22)}$. Interestingly, it has been shown in cultured hepatocytes that CPT I can be up-regulated by a PPAR $\alpha$-dependent mechanism using clofibrate and FA-CoA esters (also allowing peroxisomal proliferation) and by a PPAR $\alpha$-independent mechanism activated by non-esterified PUFA, both systems aiming at two different levels of the gene sequence ${ }^{(78)}$. If this regulation also applied to grass carp, fenofibrate would induce mainly peroxisomal activities, while NEFA released from fat tissues during fasting and entering liver cells would induce mainly CPT I activities. The former activities would allow the preferential $\beta$-oxidation of EPA and DHA, and the latter would allow the preferential $\beta$-oxidation of MUFA. However, in fish, the peroxisomal induction by fenofibrate would be of much lesser extent than that in mammals, which suggests that the peroxisomal FA oxidation pathway is very weak in normal fish and would explain the usual accumulation of dietary EPA + DHA in tissues.

\section{Lipid peroxidation}

In grass carp fed the HF diet, there was a permanent infiltration of hepatic cell lipids. This metabolic state could result from excess uptake of blood lipids as lipoproteins and NEFA, insufficient use of lipids as energetic substrates and/ or impaired lipoprotein secretion. Part of these could originate from the peroxidation of membrane lipids rich in highly unsaturated FA. Gray ${ }^{(79)}$ found a geometrical relationship between sensitivity of FA to peroxidation and degree of unsaturation. Indeed, it has been shown that high fish oil levels in diets increased the susceptibility of turbot to FA peroxidation with a clear correlation between increased malondialdehyde production and decrease in PUFA ${ }^{(80)}$. Further, Grattagliano et al. ${ }^{(66)}$ pointed out that fatty livers were often associated with low levels of antioxidants and lipid peroxidation. The present results show that, even before fasting or fenofibrate treatment, there was already a relatively elevated level of plasma malondialdehyde when compared with previous results ${ }^{(25,26)}$. Fasting represents an oxidative stress for animals ${ }^{(81-83)}$ and has been assumed to consume antioxidant stores of organs through the immediate generation of free radicals $^{(82)}$. However, in the present experiment, fasting did not change plasma malondialdehyde concentrations despite the high amounts of EPA + DHA released from adipose tissues and transported in the bloodstream (Tables 3 and 6). These data suggest that there was a plateau level of lipoperoxidation (developed by the high TBARS concentration) balanced through convenient antioxidant defences, and also suggest that there was no absolute correlation between TBARS and liver fat contents. Indeed, 1 week of fasting resulted in hepatic steatosis but without any change in plasma TBARS concentrations and, in fenofibrate-treated fish, the decrease in hepatic lipids after fenofibrate treatment was associated with increased TBARS concentrations. Hypolipidaemic agents, such as fenofibrate, are known to trigger hepatomegaly and hepatic peroxisome proliferation in rats and mice ${ }^{(84)}$. These fibrate derivatives are transformed within cells into compounds known to exhibit hepatocarcinogenic properties in the long term in rodents ${ }^{(85)}$. This might result from a metabolic imbalance due to a permanent free radical production ${ }^{(86)}$. Fenofibrate and clofibrate have also been shown to induce peroxisomal $\mathrm{H}_{2} \mathrm{O}_{2}$-generating reactions and to increase ubiquinol levels in tissues, however, without any change in plasma TBARS concentrations ${ }^{(87-90)}$. In grass carp treated by fenofibrate, the deleterious effects of $\mathrm{H}_{2} \mathrm{O}_{2}$ produced during the first steps of the peroxisomal FA oxidation pathway may be partly prevented through the increased activity of catalase. On the other hand, the increase in plasma malondialdehyde indicated that the peroxidation of unsaturated FA was insufficiently counteracted by appropriate antioxidant defences.

On the whole, grass carp fed an HF diet were shown to exhibit lipid-related properties which are close to those existing in mammals after fasting, but have a weak response towards PPAR ligands when compared with rodents and humans. This herbivorous fish species appears to represent a useful model for the investigation of mechanisms related to abnormalities of lipid metabolism.

\section{Acknowledgements}

The present study was funded by the National Natural Science Foundation of China (project no. 39970576/C020501). Z.-Y. D. designed all experiments, carried out the main experimental work and wrote the draft under the direction of project leader Y.-J. L.; P. C. and P. D. assisted with the experiment design and draft writing; W.-H. Z. provided all data of FA composition; L. F. provided important information to improve the final paper; L.-X. T. supplied healthy fish and did all the aquaculture management. The authors are also grateful to the referees for their comments for improvement. There are no personal or financial conflicts of interest. 


\section{References}

1. Forcheron F, Cachefo A, Thevenon S, Pinteur C \& Beylot M (2002) Mechanisms of the triglyceride- and cholesterol-lowering effect of fenofibrate in hyperlipidemic type 2 diabetic patients. Diabetes 51, 3486-3491.

2. Guay DR (2002) Update on fenofibrate. Cardiovasc Drug Rev 20, 281-302.

3. Liamis G, Kakafika A, Bairaktari E, Miltiadous G, Tsimihodimos V, Goudevenos J, Achimastos A \& Elisaf M (2002) Combined treatment with fibrates and small doses of atorvastatin in patients with mixed hyperlipidemia. Curr Med Res Opin 18, $125-128$.

4. Klosiewicz-Latoszek L \& Szostak WB (1991) Comparative studies on the influence of different fibrates on serum lipoproteins in endogenous hyperlipoproteinaemia. Eur J Clin Pharmacol 40, 33-41.

5. Vakkilainen J, Steiner G, Ansquer JC, Perttunen-Nio H \& Taskinen MR (2002) Fenofibrate lowers plasma triglycerides and increases LDL particle diameter in subjects with type 2 diabetes. Diabetes Care 25, 627-628.

6. Guo Q, Wang PR, Milot DP, Ippolito MC, Hernandez M, Burton CA, Wright SD \& Chao Y (2001) Regulation of lipid metabolism and gene expression by fenofibrate in hamsters. Biochim Biophys Acta 1533, 2202-2232.

7. Fruchart JC, Staels B \& Duriez P (2001) PPARs, metabolic disease and atherosclerosis. Pharmacol Res 44, 345-352.

8. Marx N, Duez H, Fruchart JC \& Staels B (2004) Peroxisome proliferator-activated receptors and atherogenesis: regulators of gene expression in vascular cells. Circ Res 94, 1168-1178.

9. Berthou L, Duverger N, Emmanuel F, et al. (1996) Opposite regulation of human versus mouse apolipoprotein A-I by fibrates in human apolipoprotein A-I transgenic mice. J Clin Invest 97, 2408-2416.

10. Frøyland L, Madsen L, Vaagenes H, Totland GK, Auwerx J, Kryvi H, Staels B \& Berge RK (1997) Mitochondrion is the principal target for nutritional and pharmacological control of triglyceride metabolism. J Lipid Res 38, 1851-1858.

11. Tsoko M, Beauseigneur F, Gresti J, Demarquoy J \& Clouet P (1998) Hypolipidaemic effects of fenofibrate are not altered by mildronate-mediated normalization of carnitine concentration in rat liver. Biochimie 80, 943-948.

12. Minnich A, Tian N, Byan L \& Bilder G (2001) A potent PPAR $\alpha$ agonist stimulates mitochondrial fatty acid $\beta$-oxidation in liver and skeletal muscle. Am J Physiol Endocrinol Metab 280, E270-E279.

13. Mancini FP, Lanni A, Sabatino L, Moreno M, Giannino A, Contaldo F, Colantuoni V \& Goglia F (2001) Fenofibrate prevents and reduces body weight gain and adiposity in diet-induced obese rats. FEBS Lett 491, 154-158.

14. Kersten S, Seydoux J, Peters JM, Gonzalez FJ, Desvergne B \& Wahli W (1999) Peroxisome proliferator-activated receptor $\alpha$ mediates the adaptive response to fasting. J Clin Invest 103, $1489-1498$.

15. Casas F, Pineau T, Rochard P, Rodier A, Daury L, Dauca M, Cabello G \& Wrutniak-Cabello C (2000) New molecular aspects of regulation of mitochondrial activity by fenofibrate and fasting. FEBS Lett 482, 71-74.

16. Ohama T, Matsuki N, Saito H, Tsukamoto K, Kinoshita M, Katsuragawa K, Okazaki S, Yamanaka M \& Teramoto T (1994) Effect of starving and refeeding on lipid metabolism in suncus. J Biochem (Tokyo) 115, 190-193.

17. Sävendahl L \& Underwood LE (1999) Fasting increases serum total cholesterol, LDL cholesterol and apolipoprotein B in healthy, nonobese humans. J Nutr 129, 2005-2008.

18. Kochan Z, Goyke E, Karbowska J, Slominska E \& Swierczynski J (2001) The decrease of rat postprandial plasma triacylglycerol concentration after multiple cycles of starvation-refeeding. Horm Metab Res 33, 26-29.

19. Vaisman N, Sklan D \& Dayan Y (1990) Effect of moderate semi-starvation on plasma lipids. Int J Obes 14, 989-996.

20. Samra JS, Clark ML, Humphreys SM, Macdonald IA \& Frayn KN (1996) Regulation of lipid metabolism in adipose tissue during early starvation. Am J Physiol 271, E541-E546.

21. Garcia-Fuentes E, Gil-Villarino A, Zafra MF \& Garcia-Peregrin E (2003) Influence of fasting status on the effects of coconut oil on chick plasma and lipoprotein composition. J Physiol Biochem 59, 101-110.

22. Andriamampandry MD, Bnouham M, Michard D, Gutbier G, Le Maho Y \& Leray C (1996) Food deprivation modifies fatty acid partitioning and $\beta$-oxidation capacity in rat liver. J Nutr 126, 2020-2027.

23. Du Z, Demizieux L, Degrace P, Gresti J, Moindrot B, Liu Y, Tian L, Cao J \& Clouet P (2004) Alteration of 20:5n-3 and $22: 6 n-3$ fat contents and liver peroxisomal activities in fenofibrate-treated rainbow trout. Lipids 39, 849-855.

24. Du ZY, Liu YJ, Tian LX, Wang JT, Wang Y \& Liang GY (2005) Effect of dietary lipid level on growth, feed utilization and body composition by juvenile grass carp (Ctenopharyngodon idella). Aquacult Nutr 11, 179-188.

25. Du ZY, Clouet P, Zheng WH, Degrace P, Tian LX \& Liu YJ (2006) Biochemical hepatic alterations and body lipid composition in the herbivorous grass carp (Ctenopharyngodon idella) fed high-fat diets. Br J Nutr 95, 905-915.

26. Du ZY, Clouet P, Huang LM, Degrace P, Zheng WH, Tian LX \& Liu YJ (2007) Utilization of different dietary lipid sources at high level in herbivorous grass carp (Ctenopharyngodon idella): mechanism related to hepatic fatty acid oxidation. Aquacult Nutr 14, 77-92.

27. Yu SK, Olsen CE \& Marcussen J (1998) Methods for the assay of 1,5-anhydro-D-fructose and $\alpha$-1,4-glucanlyase. Carbohydr Res 305, 73-82.

28. Bligh EC \& Dyer WJ (1959) A rapid method of total lipid extraction and purification. Can J Biochem Physiol 37, 911-927.

29. Koditschek LK \& Umbreit WW (1969) $\alpha$-Glycerophosphate oxidase in Streptococcus faecium F 24. J Bacteriol 98, 1063-1068.

30. Richmond W (1973) Preparation and properties of a cholesterol oxidase from Nocardia sp. and its application to the enzymatic assay of total cholesterol in serum. Clin Chem 19, 1350-1356.

31. Nakamura M, Taniguti $Y$, Yamamoto M, Hino K \& Manabe M (1997) Homogeneous assays of serum LDL-cholesterol on an automatic analyzer. Clin Chem 43, S260-S261.

32. Arranz-Pena ML, Tasende-Mata J \& Martin-Gil FJ (1998) Comparison of two homogeneous assays with a precipitation method and an ultracentrifugation method for the measurement of HDLcholesterol. Clin Chem 44, 2499-2505.

33. Steinberg KK, Cooper GR, Graiser SR \& Rosseneu M (1983) Some considerations of methodology and standardization of apolipoprotein A-I immunoassays. Clin Chem 29, 415-426.

34. Rueda-Jasso R, Conceicao LEC, Dias J, De Coen W, Gomes E, Rees JF, Soares F, Dinis MT \& Sorgeloos P (2004) Effect of dietary non-protein energy levels on condition and oxidative status of Senegalese sole (Solea senegalensis) juveniles. Aquaculture 231, 417-433.

35. Bancroft JD \& Stevens A (1977) Theory and Practice of Histopathological Techniques. Edinburgh, UK: Churchill Livingstone.

36. Clouet P, Niot I \& Bézard J (1989) Pathway of $\alpha$-linolenic acid through the mitochondrial outer membrane in the rat liver and influence on the rate of oxidation. Biochem $J \mathbf{2 6 3}$, 867-873.

37. Smith PK, Krohn RI, Hermanson GT, Mallia AK, Gartner FH, Provenzano MD, Fujimoto EK, Goeke NM, Olson BJ \& Klenk DC (1985) Measurement of protein using bicinchoninic acid. Anal Biochem 150, 76-85. 
38. Weissbach H, Smith TE, Daly JW, Witkop B \& Udenfriend S (1960) A rapid spectrophotometric assay of mono-amine oxidase based on the rate of disappearance of kynuramine. J Biol Chem 235, 1160-1163.

39. Aebi H (1974) Catalase. In Methods of Enzymatic Analysis, pp. 673-684 [HU Bergmeyer, editor]. New York: Academic Press.

40. Bronfman M, Inestrosa NC \& Leighton F (1979) Fatty acid oxidation by human liver peroxisomes. Biochem Biophys Res Commun 88, 1030-1036.

41. Bremer J (1981) The effect of fasting on the activity of liver carnitine palmitoyltransferase and its inhibition by malonylCoA. Biochim Biophys Acta 665, 628-631.

42. Chen SH, Li SF, Liu ZS, Qiu QF \& Lin LK (1992) Application of Nuclear Technology in Biology, p. 61. Guangzhou, China: Zhongshan University Press.

43. Veerkamp JH, Van Moerkerk HT, Glatz JF \& Van Hinsbergh VW (1983) Incomplete palmitate oxidation in cell-free systems of rat and human muscles. Biochim Biophys Acta 753, 399-410.

44. Du Z, Liu Y, Tian L, Wang J, Wang Y, Guo R \& Liang G (2004) The change of blood lipid indexed after fed high-fat diet in grass carp (article in Chinese). Acta Sci Natur Univ Sunyatseni 43, Suppl., 77-79.

45. Ellen RL \& McPherson R (1998) Long-term efficacy and safety of fenofibrate and a statin in the treatment of combined hyperlipidemia. Am J Cardiol 81, 60B-65B.

46. Despres JP (2001) Increasing high-density lipoprotein cholesterol: an update on fenofibrate. Am J Cardiol 88, 30N-36N.

47. Xue CY, Kageyama H, Kashiba M, Kobayashi A, Osaka T, Namba Y, Kimura S \& Inoue S (2001) Different origin of hypertriglyceridemia induced by a high-fat and a high-sucrose diet in ventromedial hypothalamic-lesioned obese and normal rats. Int J Obes Relat Metab Disord 25, 434-438.

48. Roberts CK, Barnard RJ, Liang KH \& Vaziri ND (2002) Effect of diet on adipose tissue and skeletal muscle VLDL receptor and LPL: implications for obesity and hyperlipidemia. Atherosclerosis 161, 133-141.

49. Kennish JM, Sharpdahl JL, Chambers KA, Thrower F \& Rice SD (1992) The effect of a herring diet on lipid composition, fatty acid composition, and cholesterol levels in muscle tissue of pen-reared chinook salmon Oncorhynchus tshawytscha. Aquaculture 108, 309-322.

50. Kaushik SJ, Cravedi JP, Lalles JP, Sumpter J, Fauconneau B \& Laroche M (1995) Partial or total replacement of fish meal by soya protein on growth, protein utilization, potential estrogenic or antigenic effects, cholesterolemia and flesh quality in rainbow trout. Aquaculture 133, 257-274.

51. Regost C, Arzel J, Cardinal M, Robin J, Laroche M \& Kaushik SJ (2001) Dietary lipid level, hepatic lipogenesis and flesh quality in turbot (Psetta maxima). Aquaculture 193, 291-309.

52. Du Z, Liu Y, Zheng H, Tian L \& Liang G (2002) The effects of three oil sources and two anti-fatty liver factors on the growth, nutrient compostion and serum biochemical indexes on Lateolabrax japonicus (article in Chinese). J Fish China 26, 542-550.

53. Castelli WP (1988) Cholesterol and lipids in the risk of coronary artery disease - the Framingham Heart Study. Can J Cardiol 4, Suppl. A, 5A-10A.

54. Assmann G, Schulte H, von Eckardstein A \& Huang Y (1996) High-density lipoprotein cholesterol as a predictor of coronary heart disease risk. The PROCAM experience and pathophysiological implications for reverse cholesterol transport. Atherosclerosis 124, Suppl. S11-S20.

55. Staels B, van Tol A, Andreu T \& Auwerx J (1992) Fibrates influence the expression of genes involved in lipoprotein metabolism in a tissue-selective manner in the rat. Arterioscler Thromb 12, 286-294.

56. Vu-Dac N, Chopin-Delannoy S, Gervois P, Bonnelye E, Martin G, Fruchart JC, Laudet V \& Staels B (1998) The nuclear receptors peroxisome proliferator-activated receptor $\alpha$ and Reverb $\alpha$ mediate the species-specific regulation of apolipoprotein A-I expression by fibrates. J Biol Chem 273, 25713-25720.

57. Chatzifotis S \& Takeuchi T (1997) Effect of supplemental carnitine on body weight loss, proximate and lipid compositions and carnitine content of red sea bream (Pagrus major) during starvation. Aquaculture 158, 129-140.

58. Qian YX, Cheng HQ \& Sun JF (2002) Effects of starvation on blood biochemical parameters in Japanese sea bass (Lateolabrax japonicus) (article in Chinese). J Fish Sci China 9, 133-136.

59. Yamamoto K, Fukuda N, Zhang L \& Sakai T (1996) Altered hepatic metabolism of fatty acids in rats fed a hypolipidaemic drug, fenofibrate. Pharmacol Res 33, 337-342.

60. Silva SSD, Gunasekera RM \& Austin CM (1997) Change in the fatty acid profile of hybrid red tilapia, Oreochromis mossambicus $\times O$. niloticus, subjected to short-term starvation, and a comparison with change in seawater raised fish. Aquaculture 153, 273-290.

61. Degrace P, Demizieux L, Du ZY, Gresti J, Caverot L, Djaouti L, Jourdan T, Moindrot B, Guilland JC, Hocquette JF \& Clouet P (2007) Regulation of lipid flux between liver and adipose tissue during transient hepatic steatosis in carnitine-depleted rats. J Biol Chem 282, 20816-20826.

62. Auwerx J, Schoonjans K, Fruchart JC \& Staels B (1996) Regulation of triglyceride metabolism by PPARs: fibrates and thiazolidinediones have distinct effects. J Atheroscler Thromb 3, 81-89.

63. Escher P, Braissant O, Basu-Modak S, Michalik L, Wahli W \& Desvergne B (2001) Rat PPARs: quantitative analysis in adult rat tissues and regulation in fasting and refeeding. Endocrinology 142, 4195-4202.

64. Sharma AM \& Staels B (2007) Peroxisome proliferator-activated receptor $\gamma$ (PPAR $\gamma)$ and adipose tissue - understanding obesity-related changes in regulation of lipid and glucose metabolism. J Clin Endocrinol Metab 92, 386-395.

65. Vidal-Puig A, Jimenez-Linan M, Lowell BB, Hamann A, Hu E, Spiegelman B, Flier JS \& Moller DE (1996) Regulation of PPAR $\gamma$ gene expression by nutrition and obesity in rodents. J Clin Invest 97, 2553-2561.

66. Grattagliano I, Vendemiale G, Caraceni P, Domenicali M, Nardo B, Cavallari A, Trevisani F, Bernardi M \& Altomare E (2000) Starvation impairs antioxidant defense in fatty livers of rats fed a choline-deficient diet. $J$ Nutr 130, 2131-2136.

67. Willumsen N, Hexeberg S, Skorve J, Lundquist M \& Berge RK (1993) Docosahexaenoic acid shows no triglyceride-lowering effects but increases the peroxisomal fatty acid oxidation in liver of rats. J Lipid Res 34, 13-22.

68. Willumsen N, Vaagenes H, Lie O, Rustan AC \& Berge RK (1996) Eicosapentaenoic acid, but not docosahexaenoic acid, increases mitochondrial fatty acid oxidation and upregulates 2,4-dienoyl-CoA reductase gene expression in rats. Lipids 31, $579-592$.

69. Tidwell JH, Webster CD \& Clark J (1992) Effect of feeding, starvation, and refeeding on the fatty acid composition of channel catfish, Ictalurus punctatus, tissues. Comp Biochem Physiol 103A, 365-368.

70. Mannaerts GP, Debeer LJ, Thomas J \& De Schepper PJ (1979) Mitochondrial and peroxisomal fatty acid oxidation in liver homogenates and isolated hepatocytes from control and clofibrate-treated rats. J Biol Chem 254, 4585-4595.

71. Veerkamp JH \& Van Moerkerk HT (1985) Effect of various agents and conditions on palmitate oxidation by homogenates of rat liver and rat and human skeletal muscle. Int J Biochem 17, 1163-1169.

72. Veerkamp JH \& van Moerkerk HT (1986) Peroxisomal fatty acid oxidation in rat and human tissues. Effect of nutritional state, clofibrate treatment and postnatal development in the rat. Biochim Biophys Acta 875, 301-310. 
73. Sargent JR, Tocher DR \& Bell JG (2002) The lipids. In Fish Nutrition, 3rd ed., pp. 181-257 [JE Halver and RW Hardy, editors]. San Diego, CA: Academic Press.

74. Roberts RA, James NH, Woodyatt NJ, Macdonald $\mathrm{N}$ \& Tugwood JD (1998) Evidence for the suppression of apoptosis by the peroxisome proliferator activated receptor $\alpha$ (PPAR $\alpha)$. Carcinogenesis 19, 43-48.

75. Hawkins JM, Jones WE, Bonner FW \& Gibson GG (1987) The effect of peroxisome proliferators on microsomal, peroxisomal, and mitochondrial enzyme activities in the liver and kidney. Drug Metab Rev 18, 441-515.

76. Lock EA, Mitchell AM \& Elcombe CR (1989) Biochemical mechanisms of induction of hepatic peroxisome proliferation. Annu Rev Pharmacol Toxicol 29, 145-163.

77. Thomas H, Schladt L, Knehr M \& Oesch F (1989) Effect of diabetes and starvation on the activity of rat liver epoxide hydrolases, glutathione $S$-transferases and peroxisomal $\beta$-oxidation. Biochem Pharmacol 38, 4291-4297.

78. Louet JF, Chatelain F, Decaux JF, Park EA, Kohl C, Pineau T, Girard J \& Pegorier JP (2001) Long-chain fatty acids regulate liver carnitine palmitoyltransferase I gene (L-CPT I) expression through a peroxisome-proliferator-activated receptor $\alpha(\operatorname{PPAR} \alpha)$ -independent pathway. Biochem J 354, 189-197.

79. Gray JI (1977) Measurement of lipid oxidation: a review. J Am Oil Chem Soc 55, 539-546.

80. Stephan G, Guillaume J \& Lamour F (1995) Lipid peroxidation in turbot (Scophthalmus maximus) tissue: effect of dietary vitamin $\mathrm{E}$ and dietary $n-6$ or $n-3$ polyunsaturated fatty acids. Aquaculture 130, 251-268.

81. Wohaieb SA \& Godin DV (1987) Starvation-related alterations in free radical tissue defense mechanisms in rats. Diabetes 36, $169-173$.
82. Pascual P, Pedrajas JR, Toribio F, Lopez-Barea J \& Peinado J (2003) Effect of food deprivation on oxidative stress biomarkers in fish (Sparus aurata). Chem Biol Interact 145, 191-199.

83. Morales AE, Perez-Jimenez A, Hidalgo MC, Abellan E \& Cardenete G (2004) Oxidative stress and antioxidant defenses after prolonged starvation in Dentex dentex liver. Comp Biochem Physiol C Toxicol Pharmacol 139, 153-161.

84. Palma JM, Garrido M, Rodriguez-Garcia MI \& del Rio LA (1991) Peroxisome proliferation and oxidative stress mediated by activated oxygen species in plant peroxisomes. Arch Biochem Biophys 287, 68-74.

85. Reddy JK \& Lalwani ND (1983) Carcinogenesis by hepaticperoxisome proliferators: evaluation of the risk of hypolipidemic drugs and industrial plasticizers to humans. CRC Crit Rev Toxicol 12, 1-53.

86. Bieri F \& Lhuguenot JC (1993) Toxicity of peroxisome proliferators. Biochimie 75, 263-268.

87. Elliot BM \& Elcombe CR (1987) Lack of DNA damage or lipid peroxidation measured in vivo in the rat liver following treatment with peroxisome proliferators. Carcinogenesis 8, 1213-1218.

88. Lake BG, Kozlen SL, Evans JG, Gray TJ, Young PJ \& Gangolli SD (1987) Effect of prolonged administration of clofibric acid and di-(2-ethylhexyl) phthalate on hepatic enzyme activities and lipid peroxidation in the rat. Toxicology 44, 213-228.

89. Aberg F, Zhang Y, Appelkvist EL \& Dallner G (1994) Effects of clofibrate, phthalates and probucol on ubiquinone levels. Chem Biol Interact 91, 1-14.

90. Lores Arnaiz S, Travacio M, Monserrat AJ, Cutrin JC, Llesuy S \& Boveris A (1997) Chemiluminescence and antioxidant levels during peroxisome proliferation by fenofibrate. Biochim Biophys Acta 1360, 222-228. 